\title{
A Non-Adaptive Single-Phase PLL Based on Discrete Half-Band Filtering to Suppress Severe Frequency Disturbances
}

\author{
Luis Ibarra ${ }^{1, *(\mathbb{D}}$, Pedro Ponce ${ }^{1}(\mathbb{D})$, Raja Ayyanar ${ }^{2} \mathbb{D}$ and Arturo Molina ${ }^{1} \mathbb{D}$ \\ 1 School of Engineering and Sciences, Tecnologico de Monterrey, Tlalpan 14380, Mexico; \\ pedro.ponce@tec.mx (P.P.); armolina@tec.mx (A.M.) \\ 2 School of Electrical Computer and energy Engineering, Arizona State University, \\ Tempe, AZ 85287-5706, USA; rayyanar@asu.edu \\ * Correspondence: ibarra.luis@tec.mx; Tel.: +52-55-5483-2165
}

Received: 7 February 2020; Accepted: 1 April 2020; Published: 5 April 2020

\begin{abstract}
The interconnection of new generating and storing devices to the power grid imposes the necessity of synchronizing, so the power flow can be manipulated and distributed. In the presence of an increasingly perturbed electric grid, many proposals of novel and modified synchronization techniques attained enough robustness to deal with known perturbations. However, such proposals exhibit drawbacks on their own, leaving open enhancement opportunities, mostly over their discrete implementation-e.g., sampling issues and not-considered inter/harmonics—and their inherent complexity-e.g., the need for frequency adaptability. In this work, three traditional synchronous reference frame (SRF) phase-locked loops (PLL) are modified to implement discrete filtering, such as the well-known proposals based on moving average filters (MAFs), to avoid the problems mentioned above, known for affecting the MAF's performance. This proposal makes use of discrete, efficient units modularly assembled to yield a signal's average, based on elliptic half-band filters. The proposed PLLs were tested and exhibited clear advantages-robustness against frequency disturbances-over MAF-based equivalents at standardized tests over a typical simulation environment, setting through this work an initial milestone for its verification and further incorporation in more complex synchronization topologies.
\end{abstract}

Keywords: phase-locked loops; digital filters; power systems; moving average; multi-rate

\section{Introduction}

The power grid of the future, as a concept, is taking a significant role in the planning and modification of public infrastructure. Many of the objectives that have been stated as part of the smart-grid approach or the micro-grid viewpoint are challenging conceptually and technically some old assumptions regarding power systems [1]. Mainly, the modifications at the distribution level-implying the incorporation of distributed generators, new loads, and storage systems-bring new difficulties, as the massive penetration of power electronics reduces its reliability [2]. Specifically, researchers now face the need for more robust synchronization systems to cope with domestic renewables and storage, electric vehicles, nonlinear loads, and inverters inside heavy appliances, to name a few. Even the measuring devices would necessarily face modifications, due to disturbances.

The synchronous reference frame (SRF) phase-locked loop (PLL) is, perhaps, the most used synchronization technique nowadays. Its original conceptualization has been subjected to many modifications aiming mainly at increased robustness [3]. Recent proposals have focused on positive sequence extraction, disturbances filtering, harmonics elimination, and others [4]. The performance 
of different proposals has been documented exhaustively [4-8], showing that no single PLL solves every challenge. However, a clear trend toward discrete filtering, being led by the moving average filter (MAF) approach, can be identified from the references listed above.

Discrete implementation of SRF-PLLs is now dominated by MAFs, regarded as ideal low-pass filters (LPF) as they notch their cut-off frequencies and their harmonics [9]. Nevertheless, the MAF interacts with non-harmonic frequencies, just as a first-order LPF [6], making frequency disturbances particularly harmful for the PLL performance. This problem has been faced by adding a loop to adapt the MAF's cut-off frequency; yet, non-harmonic components cannot be rejected, and sudden frequency variations would compromise the additional loop's performance and stability [10].

Besides, digital systems impose the need for discretization, which comes with its drawbacks, namely, sampling and quantization issues, transport delays, computational efficiency, aliasing, and memory usage [11]. Therefore, there are open opportunities for contributing to the improvement of SRF-PLLs and similar proposals, focusing on frequency disturbances and discrete-efficient implementation. Indeed, the usage of multi-rate (MR) systems is proposed in this work as a substitution for the MAF, to cope with the discrete requirements and, more importantly, as a means to tackle frequency-related disturbances from a non-adaptive perspective. It is worth mentioning that enabling non-adaptive MAF PLLs commonly comes with significantly increased complexity and requires an additional frequency estimator [10] — which is redundant and susceptible to frequency disturbances.

In this work, we propose a sharp transition-band LPF, attained by sequential half-band (HB) elliptical filters that take advantage of the manipulation of the sampling rate (SR) as their operating foundation. It is a novel approach, as neither MR systems nor sequential HB filtering have been reported in past related literature. Furthermore, the solutions to tackle known MAF issues seem to have moved away from the MAF itself and mostly focus on the PLL external structure or additional processing blocks $[3,10,12]$. It is shown here that HB-based PLLs exhibit enhanced performance against frequency-related disturbances at the cost of moderate dynamic losses. Then, its usage is proper for highly disturbed electric grids. Besides, this work poses a starting point for the research effort in the direction of advanced discrete filtering.

In the rest of this paper, a sufficient explanation for HBs is provided as well as their discrete-efficient implementation. Specifically, Section 2 deals with MR systems, HB realization, and their efficient implementation, including design examples for the sake of further usage. Section 3 provides the MAFs background as a cornerstone to later introduce the HB-PLL proposal; also, the tuning of the proportional-integral (PI) required controller is derived here. The relevant tests to compare MAF and HB PLLs are identified and thoroughly depicted in Section 4, whereas the resulting values and figures of merit are analyzed in Section 5. Finally, a brief discussion and the closing remarks are provided in Section 6 and Section 7, respectively.

\section{Discrete Half-Band Elliptical Filters}

A brief introduction to half-band elliptical MR filters is provided here, as their usage in the electric field is not widespread. This section intends to become a supporting guide for the tuning and implementation of such filters, clarifying some of their inherent benefits toward useful signals' manipulation and computational complexity reduction.

\subsection{Foundations}

In a digital system, the data are transferred and processed at some SR, imposed by the system's clocking. However, each subprocess can be commanded through a different SR, coming from other clocks virtually derived from the primary one. A system whose result depends on the interaction of multiple subprocesses running with different sampling time is regarded as an MR system ([13], p. 1). Operating under different SRs is useful, as the dynamics of the transfer functions in the discrete $Z$ domain vary depending on it. Furthermore, a single output can be designed as resulting from the individual tuning of such subsystems with different SRs. 
MR filtering commonly incorporates HBs as its basic building blocks ([13], p. 105); in themselves, they are LPFs that sharply reject the higher half of the bandwidth. Their design is regularly driven by the elliptic approach, which, in general, requires a particular distribution of poles and zeros over the continuous frequency space $S=\{(\sigma, \omega)\}$, resembling an ellipse by its poles' coordinates. Among their advantages, elliptic filters exhibit equiripple and the sharpest transition band from pass-band to stop-band. Furthermore, for similar filter design requirements, these filters are commonly those with the least order ([14], pp. 81, 90-91). It is not the intention of this work to cover their theoretical basis in-depth; however, some relevant properties are highlighted for the sake of the PLL design in the sequel.

The equivalence $z=\exp \left(s T_{s}\right)$, where $T_{S}$ is the sampling time, clarifies the HBs nature as follows: having the sampling time considered as the full bandwidth $T_{S}=2 \pi / \omega_{s}$, one can substitute

$$
z=\exp \left(\frac{2 \pi \sigma}{\omega_{s}}\right)\left[\cos \left(\frac{2 \pi \omega}{\omega_{s}}\right)+j \sin \left(\frac{2 \pi \omega}{\omega_{s}}\right)\right]
$$

implying that at half of the bandwidth, i.e., $\omega=\omega_{s} / 2, \operatorname{Re}(z)=0$, whereas its imaginary part depends on $\sigma$ over $S$. Moreover, elliptic filters interleave zeros and poles as expected but hold the zeros at the unit-circle; hence, the filter's transition band will match the half-band at $z= \pm j$. As a result, one specific ellipse in $S$ matches the HB requirement; precisely, one that places all the discrete zeros on the Z's left semi-plane. By doing so, all of its poles are mapped over the imaginary axis of $Z$.

The resulting transfer function $H\left(z^{2}\right)$ is a causal, stable IIR filter with a pole at the origin. Furthermore, due to the precise distribution of its poles-over the Z's imaginary axis-the filter can be attained by the combination of all-pass modules ([13], p. 132):

$$
\begin{gathered}
H\left(z^{2}\right)=H_{0}\left(z^{2}\right)+z^{-1} H_{1}\left(z^{2}\right), \\
H_{0}\left(z^{2}\right)=\prod_{i=2,4, \cdots}^{n-1} \frac{\beta_{i}+z^{-2}}{1+\beta_{i} z^{-2}}, \quad H_{1}\left(z^{2}\right)=\prod_{i=3,5, \cdots}^{n} \frac{\beta_{i}+z^{-2}}{1+\beta_{i} z^{-2}},
\end{gathered}
$$

where $n$ is the filter's order-which must be an odd integer greater or equal to three-and $i \in \mathbb{N}$. The poles and zeros of $H\left(z^{2}\right)$, can be distributed between $H_{0,1}\left(z^{2}\right)$, where the subscripts clarify the usage of the even or odd coefficients of $\beta_{i}$ accordingly - poles are ordered incrementally on the basis of their frequency, and the first pole is $z=0$.

Each factor inside the products of (2) is a second-order all-pass filter, each of which results from the direct sequencing of two first-order ones as follows:

$$
\frac{z^{-1}-\bar{\alpha}}{1-\alpha z^{-1}} \frac{z^{-1}-\alpha}{1-\bar{\alpha} z^{-1}}=\frac{z^{-2}-2 \operatorname{Re}(\alpha) z^{-1}+|\alpha|^{2}}{1-2 \operatorname{Re}(\alpha) z^{-1}+|\alpha|^{2} z^{-2}}
$$

In the case that the all-pass' pole $z=\alpha$ is constrained to exhibit $\operatorname{Re}(\alpha)=0$ as discussed above, the equivalence with (2) is direct for each $\beta_{i}=\left|\alpha_{i}\right|^{2}$.

Remarkably, the introduced all-pass modules achieve implementation efficiency due to the poles' non-existent real part, yielding a difference equation of the form

$$
y(k)=u(k-2)+\beta u(k)-\beta y(k-2),
$$

where $u(k)$ is the system's input, and $y(k)$ represents its output. Furthermore, as can be seen in Figure 1a, each all-pass filter can be implemented through polyphase branches, due to the addition in (2), implying parallel processing capabilities. 


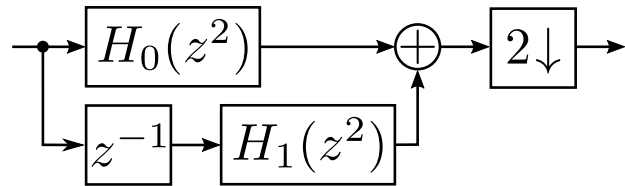

(a)

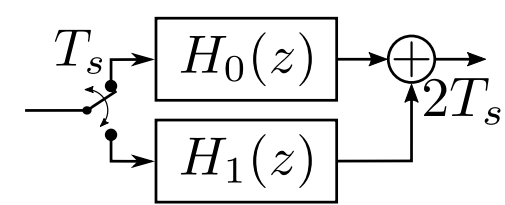

(b)

Figure 1. Schematic diagram of the proposed filter. (a) Half-band filter; (b) Efficient half-band filter.

Additionally, the HB enforces the Nyquist sampling theorem, making it possible to deliver only the useful spectrum of the incoming signal-without aliasing-by decimating the output by two, as shown in Figure 1a. Apart from changing the output's SR, such decimation and the structure shown in (4) enable the further improvement of the implementation efficiency. The branches' arrangement makes both processes be interleaved by one sample, and the decimated output implies that one from every two samples is discarded. Hence, if the input is not passed to both blocks at once but to the upper branch at instant $k$ and to the lower one at instant $k+1$-and so forth-the all-pass blocks can be processed as $H_{0,1}(z)$ instead of $H_{0,1}\left(z^{2}\right)$, generating one output per interleaving cycle. The resulting structure is shown in Figure 1b ([13], p. 113), enhancing the performance of (4) by only requiring the storage of one sample.

Interestingly, there is another advantage directly related to the PLL design practice. Up to this point, the usage of all-pass blocks was justified by the poles' placement; however, those blocks do not operate over the signal's gain but its phase. Then, the achieved attenuation is due to the elimination of signals by shifting them. Such an effect is the underlying principle of cascaded delayed signal cancellation blocks (CDSC), first proposed in [15] and used thereafter [16-18]. However, CDSCs take out individual frequencies by a $180^{\circ}$ shift-subtract process, exhibiting sampling problems and requiring as many blocks as frequencies to eliminate. On the contrary, the presented HBs can be thought of as attaining the same outcome but continuously throughout the rejected band.

\subsection{Design Process}

Here, a practical approach to HB tuning is presented. For a thorough understanding of the process, the reader can refer to the works of Jovanovic-Dolecek ([13], pp. 125-132) and Ulloa ([14], Ch. 6). Likewise, the tuning of elliptic filters has already been automated by standardized software; the MATLAB's Signal Processing Toolbox [19] is used in this work. Alternatively, the work of Ansari [20] should be revised for attaining the tuning of HBs without using MATLAB.

The design parameters of an $\mathrm{HB}$ are the pass-band ripple amplitude, the stop-band attenuation, and the width of the transition band, commonly provided as normalized frequencies. For the HB to fulfill the elliptic design requirements commented above, it must hold three conditions:

$$
f_{p}=0.5-f_{s}, \quad a_{p}=10 \log \left[1+\left(10^{a_{s} / 10}-1\right)^{-1}\right], \quad n=\frac{\log \left[\left(1+16\left(10^{a_{s} / 10}-1\right)^{2}\right)^{-1}\right]}{\log \left(\exp \left(\pi^{2} / \log \left(q^{\prime}\right)\right)\right)},
$$

which are the frequency, magnitude, and order conditions, respectively; $f_{p}$ and $f_{s}$ are the normalized frequencies for which the transition band starts and ends, respectively, divided by half;

$$
a_{p}=20 \log \left(\frac{1+\delta_{1}}{1-\delta_{1}}\right), \delta_{1}=\frac{\delta_{p}}{1-\delta_{p}}
$$

where $\delta_{p}$ is the pass-band ripple magnitude in linear scale;

$$
a_{s}=-20 \log \left(\frac{\delta_{2}}{1-\delta_{1}}\right), \delta_{2}=\delta_{s}\left(1+\delta_{1}\right),
$$


where $\delta_{s}$ is the stop-band permitted magnitude, in linear scale; and finally, according to the approximate expressions technique proposed by Lutovac et al.—cited in ([13], pp. 127-128)—for $f_{s}<\operatorname{atan}(2) / \pi \approx 0.35$,

$$
q^{\prime}=t+2 t^{5}+15 t^{9}+150 t^{13}, t=\frac{1}{2} \frac{1-\left|\tan \left(\pi f_{s}\right)\right|^{-1}}{1+\left|\tan \left(\pi f_{s}\right)\right|^{-1}} .
$$

One can see from the above equations that for a given $n$, it is possible to hold any of the design parameters and compute the other three by following the referred conditions. Indeed, the frequency condition shows that $f_{p}$ and $f_{s}$ will always be symmetrical around the half-band, whereas the magnitude condition holds $a_{p}$ and $a_{s}$ univocally. Nevertheless, having all four of the design parameters, one can compute the minimum required filter's order by considering the sharpest transition band and the smallest ripple, i.e.,

$$
f_{s}^{\prime}=\min \left[f_{s}, 0.5-f_{p}\right], \quad a_{s}^{\prime}=\max \left[a_{s},-20 \log \left(1-0.5\left(1+10^{-a_{p} / 20}\right)\right)\right] .
$$

After fulfilling the design conditions to yield the corresponding $f_{p}^{\prime}$ and $a_{p}^{\prime}$, one can compute the minimum required order as $n=e l l i p o r d(2 * f p p, 2 * f s p$, app, asp), included in MATLAB-the additional $\mathrm{p}$ in the variables' name is an indication of the tick mark.

As a result, it is possible to design the HB with an initial set of desired parameters and by deciding which to hold, as well as deciding whether the filter's order is to be fixed to a given number or its minimum required order. Finally, running [num, den] $=\operatorname{ellip}(n$, ap , as , $2 * f p$ ) outputs the numerator and denominator coefficients of the resulting IIR filter. In order to obtain $\left\{\beta_{i}\right\}$, its poles should be extracted and squared, e.g., using $b=u n i q u e(\operatorname{abs}(\operatorname{pole}(\operatorname{tf}($ num , den , -1))) . २2).

\subsection{Case-Study}

An HB was designed through the described procedure to fulfill $\delta_{p}=0.1, \delta_{s}=-40 \mathrm{~dB}, 2 f_{p}=0.45$, and $2 f_{s}=0.55$. The required filter's order resulted in $n=7$, whereas $\delta_{s}$ was set to remain unchanged. The remaining parameters fulfilling the design conditions resulted in $\delta_{p}=5 \times 10^{-5}, 2 f_{p}=0.4512$, and $2 f_{s}=0.5487$. Then, the filter's order was arbitrarily modified to be $n=5$ and $\delta_{s}$ was again fixed. The remaining parameters resulted in $\delta_{p}=5 \times 10^{-5}, 2 f_{p}=0.3782$, and $2 f_{s}=0.6218$.

Both resulting Bode plots are shown in Figure 2; it can be seen that the fixed parameters are enforced, whereas the remaining ones change accordingly; visible, in this case, over the transition band. It is noteworthy that $\delta_{s}$ is enforced throughout the stop-band. Any valid HB filter designed with the method above would exhibit a $0.7 \approx 3.1 \mathrm{~dB}$ magnitude right at the half-band, as shown as an inset on the same figure.
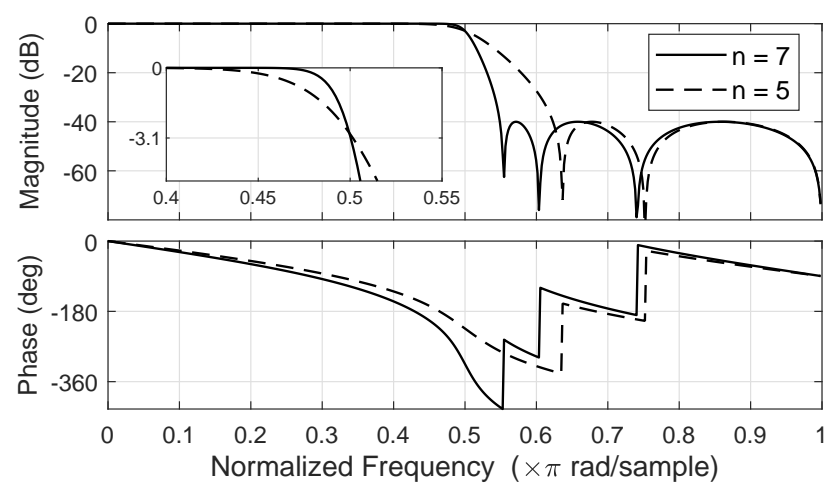

Figure 2. Bode diagram of the case-study half-band filter. 


\section{PLL Proposal}

\subsection{MAFs' Background}

The proposed PLLs in this work follow from the premises governing similar designs based on MAFs. Indeed, it involves the usage of an LPF to approximate the mean value of an incoming signal [8]. Then, the proposals at which MAFs are useful are those where the proposed HB could also be used. As a result, a justifying comparison is presented next to clarify the contribution of this proposal.

MAFs are commonly regarded as "ideal LPFs" because, although they exhibit a first-order linear LPF magnitude envelope, they notch the harmonics of the tuned cut-off frequency $\omega_{c}$. However, interharmonics do not follow such behavior, and variations in frequency-a customary consideration for PLLs design - would take the signal out of the notched areas, demanding MAF's adaptability for guaranteeing harmonics' rejection-such an effect is deeply disclosed in [10]. Moreover, their tuning is dependent on a memory window that must store $N \in \mathbb{N}$ elements according to $N T_{s}=2 \pi / \omega_{c}$; for a small $T_{s}$, memory allocation becomes inconvenient. Forcing $N$ to be an integer would preclude the previous equality, implying numeric errors, due to sampling and degrading the natural harmonics' rejection capability.

To overcome the problems derived from rounded sampling, different proposals have been tested, as mentioned in [8], mainly involving some discrete interpolation [6,18]. Although those techniques are effective, they require the incorporation of more processing elements, and sometimes, the usage of additional MAFs. It is also noteworthy that anti-aliasing considerations and additional filtering are commonly overlooked in design tasks; however, they are ultimately required for implementation, as confirmed throughout the literature where MAFs are implemented [5,6,8,10,15,21,22].

\subsection{Filtering Proposal}

In order to avoid the problems discussed so far, the usage of sequential HBs is proposed, as shown in Figure 3. For a maximum available analog to digital converter (ADC) sampling frequency $\omega_{\mathrm{ADC}}$ and a desired cut-off frequency $\omega_{\mathcal{c}}, \kappa \in \mathbb{N}$ HBs would be needed, satisfying

$$
\kappa=\left\lfloor\log _{2}\left(\omega_{\mathrm{ADC}} / \omega_{\mathcal{C}}\right)-1\right\rfloor .
$$

Indeed, the full available bandwidth will be cut, octave by octave, up to the required $\omega_{c}$. In order to enforce an integer number of HBs, $\kappa$ is rounded down, implying that the ADCs should be queried at a sampling frequency of $\omega_{s}=\kappa \omega_{c}$; such imposed SR is represented in Figure 3 with a zero-order hold $(\mathrm{ZOH})$ block.

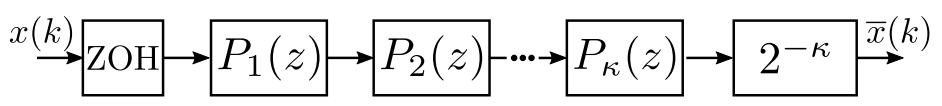

Figure 3. Full filter proposal, comprised of sequential HB modules.

The resulting structure would sequentially attenuate higher frequencies half by half, resulting in a naturally anti-aliased output. The first HBs-the outmost-are not required to exhibit sharp transition-bands or deep attenuation and can be set to have a minimum order $n=3$. The filters' characteristics can be successively enhanced to focus on low-harmonics content, only making the last $\mathrm{HB}, P_{\kappa}(z)$, match a specific transition-band. Higher-order HBs would only require the parallel computation of all-pass modules inside each $H_{0,1}(z)$. As the HBs exhibit sharp transition bands and deep attenuation, the MAF problems related to specific notching can be entirely disregarded.

Ensuring the signal's filtering requires the cut-off frequency $\omega_{\mathcal{c}}$ of $P_{\mathcal{K}}(z)$ to be below the normalized stop-band frequency $f_{s}$ for the rejection of unwanted high spectra. Then, the resulting PLL can be non-adaptive for an $\omega_{c}<\omega_{e}$, i.e., the lowest contained non-zero frequency. In this case, opposed to the MAF, frequencies around harmonic components are also filtered, avoiding interharmonics or 
harmonics after frequency jumps to greatly detriment the PLL performance. Indeed, $\omega_{e}$ can be set even lower to face negative frequency jumps, leading to the detriment of the response-speed.

From the description given in (2), and knowing that all-pass blocks have unitary gain, the resulting HB has an overall gain of two. Then, each HB should be divided by two, or, as shown in Figure 3, one only gain of $G=2^{-\kappa}$ at the end of all HBs would attain the same result. As a final note, although the PLL's adaptive version is not going to be investigated in this work, it could be attained by changing the ADCs queuing as proposed in [22]. In such a case, the normalized stop-band frequency $f_{s}$ could be manipulated to match $\omega_{e}$-notching it—ensuring the fastest possible response while not requiring the manipulation of any of the $\mathrm{HB}$ parameters.

\subsection{PID Tuning}

Tuning the proportional-integral-derivative controller (PID) customarily follows from the generic linearized model of SRF-based PLLs-depicted in Figure 4-where $\delta_{\omega, \phi}$ represent perturbations in frequency and phase, respectively, and $\tau_{p}$ is the time constant of a first order linear system that resembles the loop's bandwidth. It is noteworthy that all four relations

$$
\frac{\omega(s)}{\Delta \omega(s)}=\frac{s^{2}\left(1+s \tau_{p}\right)}{d(s)}, \quad \frac{\omega(s)}{\Delta \phi(s)}=\frac{s\left(k_{i}+k_{p} s+k_{d} s^{2}\right)}{d(s)}, \quad \frac{\hat{\phi}(s)}{\Delta \omega(s)}=\frac{s\left(1+s \tau_{p}\right)}{d(s)}, \quad \frac{\hat{\phi}(s)}{\Delta \phi(s)}=\frac{s^{2}\left(1+s \tau_{p}\right)}{d(s)}
$$

share a common denominator, i.e., $d(s)=k_{i}+k_{p} s+s^{2}+k_{d} s^{2}+s^{3} \tau_{p}$.

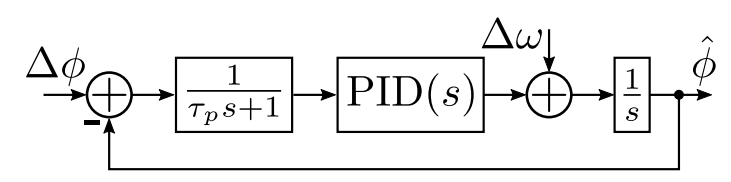

Figure 4. Linearized model of a generic SRF-PLL [5].

Such a denominator cannot be directly solved to associate the poles with the controller tuning; however, it is possible to constrain such polynomial to fulfill

$$
d(s)=\left(s+p_{1}\right)\left(s+p_{2}\right)\left(s+p_{3}\right) \quad \therefore \quad \frac{k_{i}}{\tau_{p}}=\prod_{i} p_{i}, \quad \frac{k_{p}}{\tau_{p}}=\sum_{i \neq j} p_{i} p_{j}, \quad \frac{1+k_{d}}{\tau_{p}}=\sum_{i} p_{i} .
$$

It can be seen that the poles' real part's sum must match $\left(1+k_{d}\right) / \tau_{p}$, whereas

$$
\left.\lim _{\omega \rightarrow \infty} \frac{\omega(s)}{\Delta \phi(s)}\right|_{s=j \omega}=\frac{k_{d}}{\tau_{p}}
$$

revealing that $k_{d}$ enhances the close-loop speed but enables high frequencies to affect the system through $\Delta \phi(s)$ as discussed in [6]. Accordingly, $k_{d}$ is commonly omitted-as done in this work. On the other hand, setting $k_{p}$ and $k_{i}$ up is not customary; hence, for the sake of transparency, the symmetrical optimum method used in [5] is exploited here to relate those parameters to the phase margin $\gamma$ as follows:

$$
\gamma=\arctan \sqrt{\tau_{i} / \tau_{p}}-\arctan \sqrt{\tau_{p} / \tau_{i}}, \quad \tau_{i}=\frac{k_{p}}{k_{i}}
$$

occurring at $\omega=\left(\tau_{i} \tau_{p}\right)^{-1 / 2}$.

On the other hand, it is possible to solve the poles' location in terms of $k_{i}$ and $k_{p}$ from (12) by considering $\operatorname{Re}\left\{p_{2}\right\}=\operatorname{Re}\left\{p_{3}\right\}, \operatorname{Im}\left\{p_{2}\right\}=-\operatorname{Im}\left\{p_{3}\right\}$, such as

$$
\begin{gathered}
\operatorname{Re}\left\{p_{1}\right\}=\tau_{p}^{-1}-2 \operatorname{Re}\left\{p_{2,3}\right\}, \quad \operatorname{Im}\left\{p_{1}\right\}=0, \\
k_{p}=\tau_{p} \operatorname{Im}\left\{p_{2,3}\right\}^{2}+2 \operatorname{Re}\left\{p_{2,3}\right\}-3 \tau_{p} \operatorname{Re}\left\{p_{2,3}\right\}^{2}, \quad k_{i}=\left(\operatorname{Im}\left\{p_{2,3}\right\}^{2}+\operatorname{Re}\left\{p_{2,3}\right\}^{2}\right)\left(1-2 \tau_{p} \operatorname{Re}\left\{p_{2,3}\right\}\right) .
\end{gathered}
$$


Then, if (14) is constrained to meet a $\gamma=45^{\circ}$ and the open-loop bandwidth is maximized-i.e., maximize $k_{i}$ and minimize $k_{p}$-equation (15) can be solved as

$$
k_{p}=9 \tau_{p}^{-1}(17 \sqrt{2}-24), \quad k_{i}=9 \tau_{p}^{-2}(99 \sqrt{2}-140) .
$$

This procedure avoids setting a damping parameter—like in [5] —and makes the tuning process only dependent on $\tau_{p}$.

\section{Testing Protocol}

Three SRF-PLL proposals that make direct use of MAFs were compared against their HB counterparts, namely, Delay-PLL, Derivative-PLL, and Park-PLL. Their orthogonal signal generators (OSG) - shown in Figure 5-were programmed to adapt, using the PLL's estimated frequency, so the non-adaptive nature of MAF and HB filter blocks was isolated. The linearized loop's bandwidth-see Figure 4-for both MAF and HB, were measured to slow the loop down to about $\tau_{p} \approx 0.007$ and $\tau_{p} \approx 0.009$, respectively, mostly depending on $\omega_{c}$. The PI parameters were computed directly from (16).

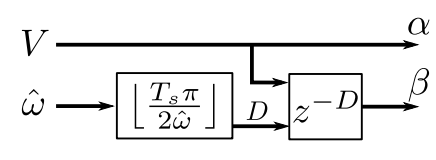

(a)

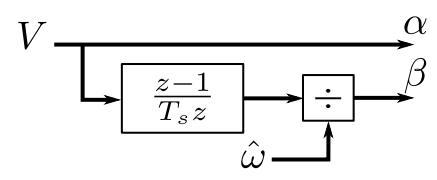

(b)

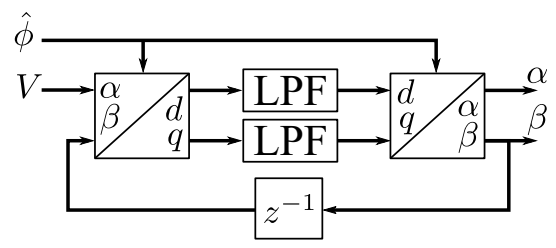

(c)

Figure 5. Tested orthogonal signal generators (OSG). (a) Delay OSG; (b) Derivative OSG; (c) Park OSG.

The PLLs' structures were taken from the work by Han et al. [5], whereas the relevant testing scenarios were identified in $[4-6,8,10,15]$ and summarized in Table 1 . Column Ph indicates single or three-phase proposals - with a one and a three, respectively. Similarly, columns $\Delta \phi$ and $\Delta \omega$ stand for phase and frequency jumps, and $\mathrm{LOH}$ stands for low-order harmonics, where the used notation refers to the harmonic order, its sequence, and its per-unit magnitude. The noise was added to the table as a standard deviation. Finally, voltage sags are reported, depending on their usage over one, two, or the three phases. All the referred works used the same system's parameters, which were replicated in this work: all were $50 \mathrm{~Hz}$ systems, having $\omega_{s}=10 \mathrm{kHz}$. In addition, all voltage signals were normalized before interacting with any PLL.

The marginal cases identified in Table 1 were taken as a benchmark for evaluating both MAF and HB PLLs. Particularly, the following tests were considered: phase jumps of $-20^{\circ}$ and $+90^{\circ}$, frequency jumps of $-3 \mathrm{~Hz}$ and $+5 \mathrm{~Hz}$, noise with $\sigma^{2}=0.05$ and $\sigma^{2}=0.01$, and voltage sags of -0.6 p.u. at $47 \mathrm{~Hz}$ and $50 \mathrm{~Hz}$. For every case, the overshoot, settling time, and frequency/phase peak-to-peak amplitudes were recorded. It is noteworthy that all tests in Table 1 disregarded interharmonics, and that frequency jumps of an already contaminated signal were only considered in [6]. As both tests would be, indeed, the first advantage of HB over MAF, two harmonics' combinations-up to the 13th harmonic, one yielding a total harmonic distortion of THD $\approx 0.08$ and another of THD $\approx 0.16$-were tested at 47,50 , and $55 \mathrm{~Hz}$, and under $+5 \mathrm{~Hz}$ and $-3 \mathrm{~Hz}$ frequency jumps. Specifically, the harmonic components are $3^{\text {rd }} 0.04,5^{\text {th }} 0.05,7^{\text {th }} 0.02,9^{\text {th }} 0.01,11^{\text {th }} 0.04,13^{\text {th }} 0.0015$; the combination yielding higher THD considered the same distribution but doubled. The phases are $3^{\text {rd } \frac{\pi}{6}}, 5^{\text {th }} \frac{-\pi}{3}, 7^{\text {th }} \frac{\pi}{2}, 9^{\text {th }} \frac{-\pi}{4}, 11^{\text {th } \frac{\pi}{3}}, 13^{\text {th }} 0$. 
Table 1. Tests' summary by reference.

\begin{tabular}{|c|c|c|c|c|c|c|}
\hline & $\mathrm{Ph}$ & $\Delta \phi\left({ }^{\circ}\right)$ & $\omega(\mathrm{Hz})$ & LOH (seq. - p.u.) & Noise $\sigma^{2}$ & Sag (p.u.) \\
\hline [10] & 1 & +40 & -2 & $\begin{array}{c}\mathrm{THD}=8 \% \\
@ 50,49,48 \mathrm{~Hz}\end{array}$ & - & - \\
\hline$[4]$ & 3 & -20 & +3 & $\begin{array}{c}1^{-} 0.10,5^{-} 0.09 \\
7^{+} 0.08,11^{-} 0.07 \\
13^{+} 0.05\end{array}$ & - & $\begin{array}{c}-0.5(3 \phi) \\
@-20^{\circ}\end{array}$ \\
\hline$[5]$ & 1 & - & +5 & $\begin{array}{c}3^{+} 0.05,5^{+} 0.05 \\
7^{+} 0.04\end{array}$ & 0.01 & - \\
\hline [6] & 3 & +90 & +5 & $\begin{array}{c}5^{-} 0.10,7^{-} 0.05 \\
11^{-} 0.05,13^{+} 0.05 \\
+5 \mathrm{~Hz}\end{array}$ & 0.01 & $\begin{array}{l}-0.4(1 \phi) \\
-0.4(2 \phi) \\
-0.4(3 \phi)\end{array}$ \\
\hline [15] & 3 & +40 & +3 & $\begin{array}{c}5^{-} 0.06,7^{+} 0.05 \\
11^{-} 0.035,13^{+} 0.03 \\
@ 47,49 \mathrm{~Hz}\end{array}$ & - & $\begin{array}{c}-0.6(1 \phi) \\
@ 49 \mathrm{~Hz} \\
@ 47 \mathrm{~Hz}\end{array}$ \\
\hline [8] & 3 & +40 & +5 & $\begin{array}{c}1^{-}[0,0.3], 5^{ \pm}[0,0.3] \\
7^{ \pm}[0,0.3], 11^{ \pm}[0,0.3]\end{array}$ & 0.05 & - \\
\hline
\end{tabular}

The HB-PLL was tuned to match $100 \mathrm{~Hz}$, and $6 \mathrm{~Hz}$ were subtracted to cope with the lowest expected frequency jump. As this frequency should match $f_{s}$, it is essential to define the final $P_{\mathcal{K}}(z)$ characteristics to hold. A sharper stop-band transition exhibits a trade-off against stop-band attenuation, whereas the improvement of any of them makes the filter's order to grow.

In this case, a 9th-order $\mathrm{HB}$ with $2 f_{s}=0.51086$ is enforced, obtaining $\beta=\{0.24,0.62,0.85,0.96\}$ with $\delta_{p}=178 \times 10^{-6}$ and $\delta_{s} \approx-34.5 \mathrm{~dB}$. As a result, the bandwidth of $P_{\mathcal{K}}(z)$ is of $184 \mathrm{~Hz}$. Using (10) yields

$$
\kappa=\left\lfloor\log _{2}\left(10 \times 10^{3} /(94)\right)-1\right\rfloor=5,
$$

implying that four additional HB filters are required and that the final, composite filter's bandwidth is of $5888 \mathrm{~Hz}$, i.e., an available sampling frequency inside $\omega_{\mathrm{ADC}}=10 \mathrm{kHz}$. The remaining HB filters are tuned as follows: $P_{3,4}(z)$ are set to be of 5 th order and to hold $\delta_{s}=-54 \mathrm{~dB}$, whereas $P_{1,2}$ of 3rd order with $\delta_{p}=-30 \mathrm{~dB}$. Such tuning parameters satisfy $f_{s}<\operatorname{atan}(2) / \pi$ in all cases.

All tests were run twice. The first set of results considers MAF-PLLs to run under an SR of $T_{\mathrm{MAF}}=100 \mu \mathrm{s}$ whereas HB-PLLs do under $T_{\mathrm{HB}}=1 / 5888 \mathrm{~s}$. Such a difference accounts for implementation considerations while adjusting the ADC on a hypothetical embedded system. The sampling time associated with the HB-PLLs is the highest possible below the assumed ADC capabilities that match (10). On the other hand, the second test makes $T_{\mathrm{MAF}}=T_{\mathrm{HB}}$ in an attempt to isolate the filters' capabilities, removing hindrances associated with the SR alone.

The simulations were performed on MATLAB-Simulink-including the DSP System Toolbox [23] to enable the downsampling operations-using the variable time-step solver ode45, enforcing different, fixed sampling times $T_{\mathrm{HB}}$ and $T_{\mathrm{MAF}}$ as needed. The initial and maximum step-sizes are set to $T_{\mathrm{MAF}}$ and the relative tolerance to $1 \times 10^{-3}$. Every SR inside the simulation was strictly revised to enable a valid comparison. The simulation was run for $2 \mathrm{~s}$, and the tested disturbance was added at $0.5 \mathrm{~s}$. The steady-state value of a signal was computed through the arithmetic mean of its last $0.25 \mathrm{~s}$, unless it did diverge, where zero was assigned.

Four parameters were acquired from every test: overshoot (OS), settling time (ST), peak to peak amplitude during steady-state (PK), and energy during steady-state (EN). The OS was calculated by first subtracting the signal's steady-state value from every sample; similarly, the ST was taken by considering the thresholds $0.25 \mathrm{~Hz}$ and $1^{\circ}$ around the computed steady-state value for frequency and phase signals, respectively. Whenever a signal oscillates but never settles below the desired threshold, a value near $1.5 \mathrm{~s}$ is reported. The PK was computed as the subtraction of the minimum from the 
maximum value of the last $0.25 \mathrm{~s}$ of the signal, after removing the steady-state mean. Finally, the EN was calculated as

$$
\mathrm{EN}=\frac{1}{N} \sum_{n}(f(n)-\bar{f})^{2},
$$

where $N$ is the total number of samples $n$ contained in the last 0.25 s of the captured signal, and $\bar{f}$ is the signal's steady-state mean.

\section{Results}

Results for MAF-PLLs and HB-PLLs from the identified tests usually performed over SRF-PLLs and are shown in Table 2. All values were taken for both the frequency $(\omega)$ and phase $(\phi)$ errors. Similarly, Table 3 shows the performance of HB-PLLs under harmonics-related disturbances. Both tables introduced above considered $T_{\mathrm{MAF}}=100 \mu \mathrm{s}$ and $T_{\mathrm{HB}}=1 / 5888 \mathrm{~s}$. On the contrary, Tables 4 and 5 show the same set of tests but having $T_{\mathrm{MAF}}=T_{\mathrm{HB}}=1 / 5888 \mathrm{~s}$.

MAF-PLLs were compared against their non-filtered versions-the MAF was bypassed-and HB-PLLs against MAF-PLLs. Considering a 20\% threshold, a worse result was underlined, and a better one was boldfaced. The values that fell below this threshold were grayed out, as they can be considered to be similar. It is noteworthy that the unfiltered PLLs are not normally considered when testing MAF proposals.

An alluring observation can be made from Tables 2 and 4: the PLLs' performance, over OS and ST, does not clearly improve after a MAF is added. This implies that a valid justification for incorporating such a filter does not rely on the PLL's dynamic performance, but on its harmonics' rejection capability alone. The MAF non-adaptive version offers no further benefit than a simple first-order filter for a system prone to inter-harmonics or frequency disturbances and variations.

Table 2 shows that HB-PLLs are overall slower and sometimes more sensitive to the considered disturbances as foreseen. The phase accumulation yielded from the successive connection of HB blocks ends up dragging $\tau_{p}$ below the MAF speed, making the PI tuning in the continuous domain exhibit differences when exposed to such phase-lag and harder discretization conditions-even if sampled at $T_{\mathrm{HB}}$, the $\kappa^{\text {th }} \mathrm{HB}$ generates a valid output every $2^{\kappa} T_{\mathrm{HB}}$ seconds. However, for the PK and EN tests, it is possible to see consistent improvement whenever the disturbance is frequency-related. It is noteworthy that most of the underlined values under the PK and EN columns are indeed worse than those from MAF-PLLs but are also acceptable on an absolute scale as they commonly show values in the $10^{-3}$ order. For the sake of visual clarity, the results obtained from the $55 \mathrm{~Hz}$ and the $+5 \mathrm{~Hz}$ tests under $8 \%$ harmonics conditions - the first part of Table 3-are shown in Figure 6.

When operating over the nominal frequency-55 Hz in this case-the harmonic components no longer match the MAF notches but the MAF's first-order LPF envelope; this lack of attenuation is later tangible as disturbances, shown in Figure 6b. On the contrary, as the HB covers the entire rejection bandwidth, such frequency displacement poses no problems to the filter's behavior, as shown in Figure 6a-it was time-scaled to show one full period of the error signal at steady-state. Similarly, the phase errors, depicted in Figure $6 c, d$, exhibit a similar operating condition. Numerically, the MAF alternatives had a frequency PK of about 47,60, and 33 times higher than the HB ones for the Delay-PLL, Deriv-PLL, and Park-PLL, respectively. In the case of the phase, the MAF angle PKs were about 9, 10, and 17 times higher.

The dynamic performance of both proposals after applying a $+5 \mathrm{~Hz}$ frequency jump is presented in Figure 6e,f. As shown before, the MAF performance is disturbed after approaching zero; however, there is a noticeable difference for the MAF-Delay specifically, highlighted with an inset. The MAF-Delay behavior differs from that of Figure 6b, even though they both reach $55 \mathrm{~Hz}$. Given that such difference eventually ceases, the disturbed state can be attributed to dynamic difficulties experienced by the associated controller after the frequency jump. The shown frequency signals are responsible for phase disturbances, shown in Figure 6h. Due to the problems commented before, 
the MAF-Delay exhibits periodic sags that impede reaching steady-state. This dynamic issue is not present on the HB alternatives, as it can be seen in Figure 6e,g.

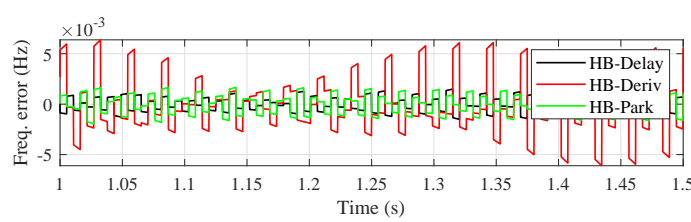

(a)

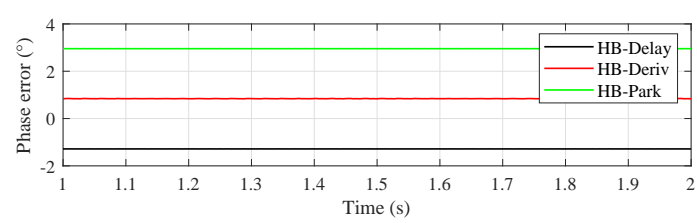

(c)

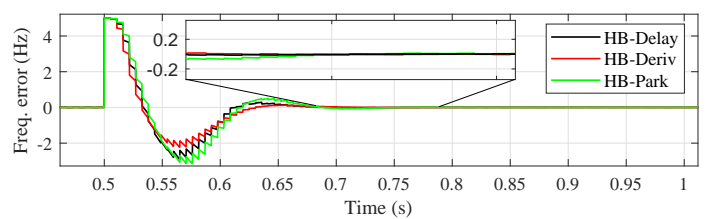

(e)

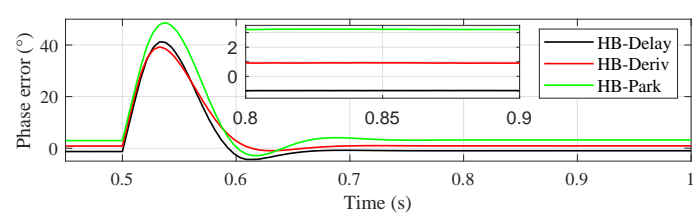

(g)

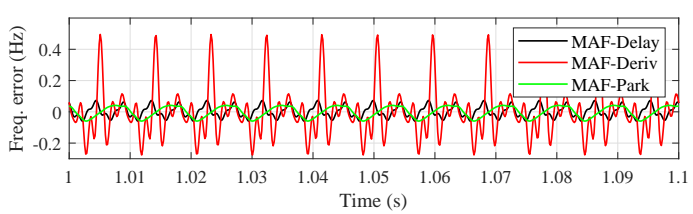

(b)

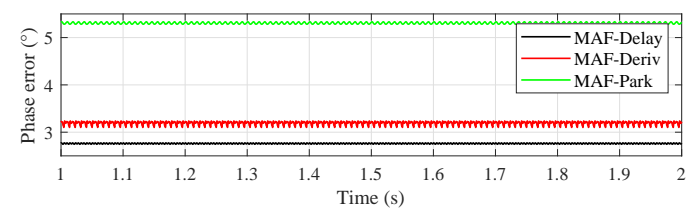

(d)

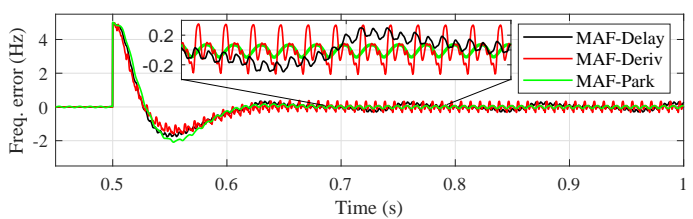

(f)

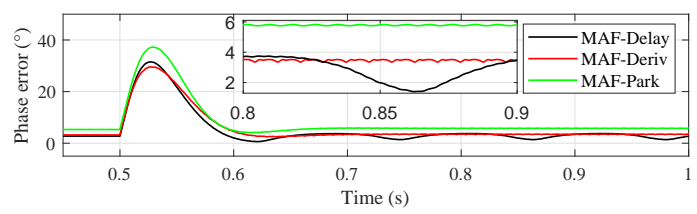

(h)

Figure 6. Frequency and phase errors for PLLs under frequency disturbances and THD $\approx 8 \%$. (a) HB frequency error at steady-state at $55 \mathrm{~Hz}$; (b) MAF frequency error at steady-state at $55 \mathrm{~Hz}$; (c) HB phase error at steady-state at $55 \mathrm{~Hz}$; (d) MAF phase error at steady-state at $55 \mathrm{~Hz}$; (e) $\mathrm{HB}$ frequency error with $+5 \mathrm{~Hz}$; (f) MAF frequency error with $+5 \mathrm{~Hz}$; (g) $\mathrm{HB}$ phase error with $+5 \mathrm{~Hz}$; (h) MAF phase error with $+5 \mathrm{~Hz}$.

In terms of the dynamic performance of both approaches, it is clear that the HB alternatives exhibit larger overshoots and are "slower," in general. On the one hand, among the three tested PLLs, frequency overshoots are between $36 \%$ and $64 \%$ higher. However, on the other hand, only the MAF-Park alternative settles—oscillates into the $0.25 \mathrm{~Hz}$ band-for which its corresponding HB alternative performs $56 \%$ slower. In the case of the phase, $\mathrm{HB}$ alternatives exhibit an overshoot about $30 \%$ larger. In contrast, the settling time is only $7 \%$ larger for the HB-Delay, $57 \%$ for the HB-Deriv, and the Park alternative cannot be compared as the MAF-Park does not settles inside the $1^{\circ}$ band.

The dynamic impediments of HB-PLLs discussed above can be partly adduced to the ratio present between the tested SRs, i.e., $T_{\mathrm{MAF}} / \mathrm{T}_{\mathrm{HB}} \approx 0.59$. Table 4 shows that whereas MAF-PLLs exhibit a very similar performance against their unfiltered PLL versions than in Table 2, HB-PLLs drastically closed the gap toward their MAF counterpart. Therefore, the imposed SR by the successive HB filtering impedes its derived PLLs to reach standard operating conditions; however, when compared at such SR, their behavior could not be immediately distinguished from MAF proposals. 
Table 2. Results from conventional tests over SRF-PLL systems with $T_{\mathrm{MAF}} \neq T_{\mathrm{HB}}$. Underlined values are those worse than the "reference" whereas boldfaced ones are those better, both by 20\%; grayed out values are considered to exhibit similar performance. MAF-PLLs are tested against non-filtered PLLs and HB-PLLs against MAF-PLLs. For the sake of brevity and data homogenization, a shorthand for scientific notation is used, i.e., $a \times 10^{b}=a \mathrm{E} b$.

\begin{tabular}{|c|c|c|c|c|c|c|c|c|c|c|c|c|c|c|c|c|c|c|c|c|c|c|c|c|c|}
\hline & & \multicolumn{4}{|c|}{ MAF-Delay } & \multicolumn{4}{|c|}{ MAF-Deriv } & \multicolumn{4}{|c|}{ MAF-Park } & \multicolumn{4}{|c|}{ HB-Delay } & \multicolumn{4}{|c|}{ HB-Deriv } & \multicolumn{4}{|c|}{ HB-Park } \\
\hline & & os & ST & PK & EN & os & ST & PK & EN & os & ST & PK & EN & os & ST & PK & EN & os & ST & PK & EN & os & ST & PK & EN \\
\hline$-20^{\circ}$ & $\omega$ & $3.06 \mathrm{E}+00$ & $9.65 \mathrm{E}-02$ & $2.35 \mathrm{E}-13$ & $9.59 \mathrm{E}-27$ & $2.99 \mathrm{E}+00$ & $9.29 \mathrm{E}-02$ & $2.62 \mathrm{E}-13$ & $1.07 \mathrm{E}-26$ & $2.87 \mathrm{E}+00$ & $9.88 \mathrm{E}-02$ & $2.80 \mathrm{E}-13$ & $1.57 \mathrm{E}-26$ & $3.07 \mathrm{E}+00$ & 1.14E- -01 & $5.30 \mathrm{E}-04$ & $2.28 \mathrm{E}-0.8$ & $3.35 \mathrm{E}+00$ & $1.19 \mathrm{E}-01$ & $7.67 \mathrm{E}-04$ & $3.59 \mathrm{E}-08$ & $2.95 \mathrm{E}+00$ & $1.19 \mathrm{E}-01$ & $1.78 \mathrm{E}-03$ & $3.18 \mathrm{E}-07$ \\
\hline & $\phi$ & $9.16 \mathrm{E}+00$ & EE-01 & 12 & $E-24$ & $\mathrm{E}+00$ & $8 E-01$ & 12 & 24 & 01 & 02 & 12 & -24 & $E+01$ & $\mathrm{BE}-01$ & $\frac{97 \mathrm{E}-04}{4}$ & $7.69 \mathrm{E}-09$ & $3 \mathrm{E}+00$ & $\overline{1.13 \mathrm{E}-01}$ & $7.71 \mathrm{E}-04$ & $1.43 \mathrm{E}-08$ & $.42 \mathrm{E}+01$ & $1.49 \mathrm{E}-01$ & $1.76 \mathrm{E}-03$ & $.19 \mathrm{E}-07$ \\
\hline$+90^{\circ}$ & $\omega$ & $-1.05 \mathrm{E}+01$ & 1E-01 & $2.17 \mathrm{E}-13$ & $17 \mathrm{E}-26$ & $-9.48 \mathrm{E}+00$ & $\mathrm{BE}-01$ & $2.62 \mathrm{E}-13$ & 26 & $1 \mathrm{E}+01$ & $1.34 \mathrm{E}-01$ & -13 & $=26$ & $10 \mathrm{E}+01$ & $1.85 \mathrm{E}-01$ & $1.06 \mathrm{E}-03$ & $6.94 \mathrm{E}-08$ & $-9.82 \mathrm{E}+00$ & $1.52 \mathrm{E}-01$ & $6.92 \mathrm{E}-04$ & $3.57 \mathrm{E}-08$ & $-1.02 \mathrm{E}+01$ & $2.06 \mathrm{E}-01$ & $1.74 \mathrm{E}-03$ & $3.20 \mathrm{E}-07$ \\
\hline & $\phi$ & $-2.67 \mathrm{E}+01$ & $22 \mathrm{E}-01$ & $6.56 \mathrm{E}-12$ & $1.55 \mathrm{E}-24$ & $-2.14 \mathrm{E}+01$ & $1.31 E-01$ & $6.56 \mathrm{E}-12$ & $1.55 \mathrm{E}-24$ & $-2.93 \mathrm{E}+01$ & $1.71 \mathrm{E}-01$ & $6.41 \mathrm{E}-12$ & $1.61 \mathrm{E}-24$ & $-4.30 \mathrm{E}+01$ & $1.82 \mathrm{E}-01$ & $1.04 \mathrm{E}-03$ & $2.28 \mathrm{E}-08$ & $-3.42 \mathrm{E}+01$ & $1.86 \mathrm{E}-01$ & 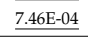 & $1.51 \mathrm{E}-08$ & $-4.44 \mathrm{E}+01$ & $1.97 \mathrm{E}-01$ & $1.72 \mathrm{E}-03$ & $1.19 \mathrm{E}-07$ \\
\hline-3 & $\omega$ & $1.04 \mathrm{E}+$ & $3 \mathrm{E}-02$ & E-03 & 7E-06 & $8.77 \mathrm{E}-01$ & FE-02 & $7.98 \mathrm{E}-03$ & $7.97 \mathrm{E}-06$ & 1.12 $\mathrm{E}+00$ & 35E-02 & $3.19 \mathrm{E}-02$ & $1.27 \mathrm{E}-04$ & $2.05 E+00$ & $9,77 \mathrm{E}-02$ & $7.58 \mathrm{E}-04$ & $6.54 \mathrm{E}-08$ & $1.57 \mathrm{E}+00$ & -01 & $1.33 \mathrm{E}-03$ & $1.84 \mathrm{E}-07$ & $1.83 \mathrm{E}+00$ & $1.52 \mathrm{E}-0$ & $68 \mathrm{E}-0 \mathrm{z}$ & 06 \\
\hline $\mathrm{Hz}$ & $\phi$ & $-1.55 \mathrm{E}+01$ & 1E-02 & E-03 & $4 \mathrm{E}-07$ & $-1.35 \mathrm{E}+01$ & $54 \mathrm{E}-02$ & 87F-03 & E-06 & $-1.47 \mathrm{E}+01$ & $8.71 \mathrm{E}-02$ & $\begin{array}{l}1.94 \mathrm{E}-02 \\
\end{array}$ & $4.73 \mathrm{E}-05$ & $-2.65 \mathrm{E}+01$ & $1.29 \mathrm{E}-01$ & $7.05 \mathrm{E}-04$ & $2.10 \mathrm{E}-08$ & $-2.30 \mathrm{E}+01$ & $1.66 \mathrm{E}-02$ & $1.25 \mathrm{E}-03$ & $7.56 \mathrm{E}-08$ & $-2.40 \mathrm{E}+01$ & $1.46 \mathrm{E}-01$ & $4.96 \mathrm{E}-03$ & $1.02 \mathrm{E}-06$ \\
\hline+5 & $\omega$ & $-1.81 \mathrm{E}+00$ & 03E-01 & $\mathrm{E}-02$ & $0 \mathrm{E}-05$ & $-1.40 \mathrm{E}+00$ & .10E-01 & 32E-02 & $2.17 \mathrm{E}-05$ & $-2.06 \mathrm{E}+00$ & $9.84 \mathrm{E}-02$ & $4.50 \mathrm{E}-02$ & $2.53 \mathrm{E}-04$ & $-3.04 \mathrm{E}+00$ & $1.36 \mathrm{E}-01$ & $1.06 \mathrm{E}-03$ & $1.22 \mathrm{E}-07$ & $-2.26 \mathrm{E}+00$ & $1.19 \mathrm{E}-01$ & $7.46 \mathrm{E}-04$ & $5.53 \mathrm{E}-08$ & $-3.20 \mathrm{E}+00$ & $1.63 \mathrm{E}-01$ & $.33 \mathrm{E}-03$ & $4 \mathrm{E}-07$ \\
\hline $\mathrm{Hz}$ & $\phi$ & $3.16 \mathrm{E}+01$ & $9.46 \mathrm{E}-02$ & $6.24 \mathrm{E}-03$ & $4.87 \mathrm{E}-06$ & $2.91 \mathrm{E}+01$ & $1.01 E-01$ & .87E- 03 & $\begin{array}{r}5.90 \mathrm{E}-06 \\
\end{array}$ & $3.58 \mathrm{E}+01$ & $1.34 \mathrm{E}-01$ & $2.34 \mathrm{E}-02$ & $6.87 \mathrm{E}-05$ & $4.23 \mathrm{E}+01$ & $\overline{1.51 \mathrm{E}-01}$ & $1.05 E-03$ & $5.08 \mathrm{E}-08$ & $\overline{3.94 \mathrm{E}+01}$ & $1.59 \mathrm{E}-01$ & $7.30 \mathrm{E}-04$ & $2.28 \mathrm{E}-08$ & $4.88 \mathrm{E}+01$ & $\overline{1.55 \mathrm{E}-01}$ & $2.26 \mathrm{E}-03$ & $2.54 \mathrm{E}-07$ \\
\hline$\sigma^{2}=$ & $\omega$ & $-1.01 \mathrm{E}+00$ & $1.50 \mathrm{E}+00$ & $4 \mathrm{E}+00$ & $6.50 \mathrm{E}-02$ & $-2.28 \mathrm{E}+00$ & $0 \mathrm{E}+00$ & $6 \mathrm{E}+00$ & & $-1.02 \mathrm{E}+00$ & $1.50 \mathrm{E}+00$ & $1.26 \mathrm{E}+00$ & $8.67 \mathrm{E}-02$ & $-1.19 \mathrm{E}+00$ & $1.50 \mathrm{E}+00$ & $1.66 \mathrm{E}+00$ & $1.26 \mathrm{E}-01$ & & $1.49 \mathrm{E}+00$ & $2.21 E+00$ & 2.71E-01 & $-1.20 \mathrm{E}+00$ & $1.50 \mathrm{E}+00$ & $1.84 \mathrm{E}+00$ & $1.61 \mathrm{E}-01$ \\
\hline 0.05 & $\phi$ & $5.70 \mathrm{E}+00$ & $1.50 \mathrm{E}+00$ & $4 \mathrm{E}+00$ & $1.19 \mathrm{E}+00$ & $5.67 \mathrm{E}+00$ & $1.50 \mathrm{E}+00$ & $4.82 \mathrm{E}+00$ & $1.30 \mathrm{E}+00$ & $7.40 \mathrm{E}+00$ & $1.50 \mathrm{E}+00$ & $4.72 \mathrm{E}+00$ & $1.48 \mathrm{E}+00$ & $-4.91 \mathrm{E}+00$ & $1.50 \mathrm{E}+00$ & $6.84 \mathrm{E}+00$ & $3.31 \mathrm{E}+00$ & $-3.30 \mathrm{E}+00$ & ${ }^{1.50 \mathrm{E}+00}$ & $7.02 \mathrm{E}+00$ & $3.28 \mathrm{E}+00$ & $-1.45 \mathrm{E}+00$ & $1.50 \mathrm{E}+00$ & $7.71 \mathrm{E}+00$ & $4.14 \mathrm{E}+0 \mathrm{C}$ \\
\hline$\sigma^{2}=$ & $\omega$ & -3.9 & $7 \mathrm{~F}+00$ & 6E-01 & -02 & $-1.02 \mathrm{E}+00$ & $\mathrm{E}+00$ & & 3.95E- -22 & 01 & +00 & $5.66 \mathrm{E}-01$ & & - & $\mathrm{E}+00$ & 01 & $\mathrm{E}-02$ & & +00 & & $\underline{\underline{v}}$ & & $\mathrm{E}+00$ & $0 \mathrm{E}-01$ & -02 \\
\hline 0.01 & $\phi$ & $3.48 \mathrm{E}+00$ & $20 \mathrm{E}+00$ & 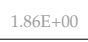 & $2.31 \mathrm{E}-01$ & $4.05 \mathrm{E}+00$ & $6 \mathrm{E}+00$ & $4 \mathrm{E}+00$ & $2.60 \mathrm{E}-01$ & $5.41 \mathrm{E}+00$ & $1.46 \mathrm{E}+00$ & $2.11 E+00$ & $2.95 \mathrm{E}-011$ & $\overline{-2.34 \mathrm{E}+00}$ & $1.49 \mathrm{E}+00$ & $3.04 \mathrm{E}+00$ & $6.53 \mathrm{E}-01$ & $-1.05 \mathrm{E}+00$ & 1.49E+00 & $3.09 \mathrm{E}+00$ & $\overline{6.41 \mathrm{E}-01}$ & -011 & $1.50 \mathrm{E}+00$ & $3.42 \mathrm{E}+00$ & $8.27 \mathrm{E}-01$ \\
\hline$-0.6 \mathrm{p} . \mathrm{u}$ & $\omega$ & $105 \mathrm{E}+0$ & 1.41E- 02 & (2) & 875.07 & -01503 & (2) & 1950? & $\pi$ & . & $969 \mathrm{E}-0$ & 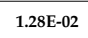 & ( & & $324 \mathrm{~T}$ & 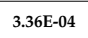 & 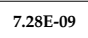 & $177 \mathrm{~F}$ & 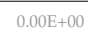 & $155 \mathrm{~F}$ & & (17) & 4 & 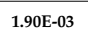 & 07 \\
\hline $147 \mathrm{~Hz}$ & $\phi$ & $5.68 \mathrm{E}+00$ & $8.39 \mathrm{E}-02$ & $7.53 \mathrm{E}-04$ & $6.94 \mathrm{E}-08$ & $2.45 \mathrm{E}+00$ & $0.00 \mathrm{E}+00$ & $1.95 \mathrm{E}-03$ & $4.73 \mathrm{E}-07$ & $1.14 \mathrm{E}+01$ & $2.06 \mathrm{E}-01$ & $7.83 \mathrm{E}-03$ & $7.57 \mathrm{E}-06$ & $2.99 \mathrm{E}+00$ & $9.60 \mathrm{E}-02$ & $3.25 \mathrm{E}-04$ & $3.71 \mathrm{E}-09$ & $7.35 \mathrm{E}-01$ & $0.00 \mathrm{E}+00$ & $4.89 \mathrm{E}-04$ & $9.92 \mathrm{E}-09$ & $9.38 \mathrm{E}+00$ & $2.48 \mathrm{E}-01$ & $2.15 \mathrm{E}-03$ & $2.53 \mathrm{E}-07$ \\
\hline$-0.6 \mathrm{~F}$ & $\omega$ & $9.90 \mathrm{E}-01$ & $1.39 \mathrm{E}-02$ & $9.22 \mathrm{E}-07$ & 9E-14 & $7.36 \mathrm{E}-03$ & $0.00 \mathrm{E}+00$ & $6.48 \mathrm{E}-10$ & 2.09E-20 & & 7TE-1 & & & $9.41 \mathrm{E}-01$ & $3.24 \mathrm{E}-02$ & 85E- & $5.36 \mathrm{E}-09$ & $-1.19 \mathrm{E}-02$ & $0.00 \mathrm{E}+00$ & $1.99 \mathrm{E}-$ & 59 & 00 & 8E- & 01E-04 & 08 \\
\hline $\mathbb{Q}_{50} \mathrm{H}_{2}$ & $\phi$ & $5.73 \mathrm{E}+00$ & $8.24 \mathrm{E}-02$ & $6.82 \mathrm{E}-06$ & $6.33 \mathrm{E}-12$ & $2.61 \mathrm{E}+00$ & $\mathrm{EE}+00$ & $6.33 \mathrm{E}-09$ & 5.58E-18 & $1.10 E+U$ & $2.044 E-01$ & $=05$ & $26 \mathrm{E}-10$ & $2.56 \mathrm{E}+00$ & $9.51 \mathrm{E}-02$ & $2.96 \mathrm{E}-04$ & $2.99 \mathrm{E}-09$ & $\frac{7.75 \mathrm{E}-01}{7}$ & $0.00 \mathrm{E}+00$ & $1.87 \mathrm{E}-04$ & $\frac{1.43 \mathrm{E}-09}{1.09}$ & $8.96 \mathrm{E}+00$ & $2.46 \mathrm{E}-01$ & $1.29 \mathrm{E}-03$ & $7.99 \mathrm{E}-08$ \\
\hline P. & $\omega$ & 9.2 & $1.35 \mathrm{E}-022$ & Do & 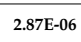 & $\mathrm{EE}-0$. & & $77 \mathrm{E}-03$ & tos & 00 & 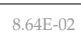 & tit-0.2 & 年 & $2 E=0$ & $24 \mathrm{E}-02$ & 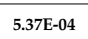 & 2.07L-00 & $-1.11 \mathrm{tL}-022$ & & $2.00 \mathrm{E}-04$ & & & $8 \mathrm{BE}-02$ & 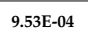 & \\
\hline & $\phi$ & $5.36 \mathrm{E}+00$ & $8.22 \mathrm{E}-02$ & $2.50 \mathrm{E}-03$ & $7.77 \mathrm{E}-07$ & $2.87 \mathrm{E}+00$ & $0.00 \mathrm{E}+00$ & $2.74 \mathrm{E}-03$ & $9.41 E-07$ & $1.06 \mathrm{E}+01$ & $2.01 E-01$ & $9.41 \mathrm{E}-03$ & 1.1.0E-05 & $1.88 \mathrm{E}+00$ & $9.65 \mathrm{E}-02$ & $5.62 \mathrm{E}-04$ & $9.98 \mathrm{E}-09$ & $\overline{8.50 \mathrm{E}-01}$ & $0.00 \mathrm{E}+00$ & $2.68 \mathrm{E}-04$ & $3.54 \mathrm{E}-09$ & $8.68 \mathrm{E}+00$ & $2.44 \mathrm{E}-01$ & $1.50 \mathrm{E}-03$ & $9.24 \mathrm{E}-08$ \\
\hline
\end{tabular}

Table 3. Results from two harmonics tests over SRF-PLL systems with $T_{\mathrm{MAF}} \neq T_{\mathrm{HB}}$. Underlined values are those worse than the MAF-PLL equivalent, whereas boldfaced ones are those better, both by $20 \%$; grayed out values are considered to exhibit similar performance. For the sake of brevity and data homogenization, a shorthand for scientific notation is used, i.e., $a \times 10^{b}=a \mathrm{E} b$.

\begin{tabular}{|c|c|c|c|c|c|c|c|c|c|c|c|c|c|c|c|c|c|c|c|c|c|c|c|c|c|}
\hline & & \multicolumn{12}{|c|}{ THD $\approx 8 \%$} & \multicolumn{12}{|c|}{ THD $\approx 16 \%$} \\
\hline & & \multicolumn{4}{|c|}{ HB-Delay } & \multicolumn{4}{|c|}{ HB-Deriv } & \multicolumn{4}{|c|}{ HB-Park } & \multicolumn{4}{|c|}{ HB-Delay } & \multicolumn{4}{|c|}{ HB-Deriv } & \multicolumn{4}{|c|}{ HB-Park } \\
\hline & & os & ST & PK & EN & os & ST & PK & EN & os & ST & PK & EN & os & ST & PK & EN & os & ST & PK & EN & os & ST & PK & EN \\
\hline @47 & $\omega$ & $-1.56 \mathrm{E}-01$ & $0.00 \mathrm{E}+00$ & $1.47 \mathrm{E}-03$ & $1.63 \mathrm{E}-07$ & $-2.52 \mathrm{E}-01$ & $1.61 \mathrm{E}-02$ & $1.34 \mathrm{E}-02$ & $1.21 \mathrm{E}-05$ & $-1.30 \mathrm{E}-01$ & $0.00 \mathrm{E}+00$ & $6.31 \mathrm{E}-03$ & $4.37 \mathrm{E}-06$ & $-3.86 \mathrm{E}-01$ & $1.61 \mathrm{E}-02$ & $2.83 \mathrm{E}-03$ & $6.05 \mathrm{E}-07$ & $-6.79 \mathrm{E}-01$ & $1.30 \mathrm{E}-01$ & $2.78 \mathrm{E}-02$ & $9.62 \mathrm{E}-05$ & $-3.33 \mathrm{E}-01$ & $1.61 \mathrm{E}-02$ & $1.02 \mathrm{E}-02$ & 1.15E-05 \\
\hline $\mathrm{Hz}$ & $\phi$ & $-9.49 \mathrm{E}-01$ & $0.00 \mathrm{E}+00$ & $1.16 \mathrm{E}-02$ & $1.52 \mathrm{E}-05$ & $1.51 \mathrm{E}-01$ & $0.00 \mathrm{E}+00$ & $4.27 \mathrm{E}-02$ & $1.23 \mathrm{E}-04$ & $2.05 \mathrm{E}+00$ & $0.00 \mathrm{E}+00$ & $8.10 \mathrm{E}-03$ & $3.17 \mathrm{E}-06$ & $-1.67 \mathrm{E}+00$ & $2.67 \mathrm{E}-02$ & $2.81 \mathrm{E}-02$ & 9.58E-05 & $-7.75 \mathrm{E}-01$ & $3.33 \mathrm{E}-02$ & $7.74 \mathrm{E}-02$ & 4.14E-04 & $1.37 \mathrm{E}+00$ & $3.48 \mathrm{E}-02$ & $1.30 \mathrm{E}-02$ & $9.87 \mathrm{E}-06$ \\
\hline$@ 50$ & $\omega$ & $\begin{array}{l}-1.52 \mathrm{E}-01 \\
\end{array}$ & $0.00 \mathrm{E}+00$ & $3.81 \mathrm{E}-03$ & $1.41 \mathrm{E}-06$ & $-2.32 \mathrm{E}-01$ & $0.00 \mathrm{E}+00$ & $1.17 \mathrm{E}-02$ & $9.25 \mathrm{E}-06$ & $-1.17 \mathrm{E}-01$ & $0.00 \mathrm{E}+00$ & $2.39 \mathrm{E}-03$ & $6.15 \mathrm{E}-07$ & $-3.73 \mathrm{E}-01$ & $1.61 \mathrm{E}-02$ & $9.15 \mathrm{E}-03$ & $8.78 \mathrm{E}-06$ & $-6.14 \mathrm{E}-01$ & $7.05 \mathrm{E}-02$ & $2.22 \mathrm{E}-02$ & $3.60 \mathrm{E}-05$ & $-3.09 \mathrm{E}-01$ & $1.61 \mathrm{E}-02$ & $3.95 \mathrm{E}-03$ & $1.77 \mathrm{E}-06$ \\
\hline $\mathrm{Hz}$ & $\phi$ & $-1.14 \mathrm{E}+00$ & $0.00 \mathrm{E}+00$ & $1.24 \mathrm{E}-02$ & $1.73 \mathrm{E}-05$ & $2.34 \mathrm{E}-01$ & $0.00 \mathrm{E}+00$ & $3.15 \mathrm{E}-02$ & $9.93 \mathrm{E}-05$ & $2.24 \mathrm{E}+00$ & $0.00 \mathrm{E}+00$ & $\overline{3.59 \mathrm{E}-03}$ & $6.94 \mathrm{E}-07$ & $-1.81 \mathrm{E}+00$ & $\overline{2.51 \mathrm{E}-02}$ & $3.06 \mathrm{E}-02$ & $\overline{1.09 E-04}$ & $-6.13 \mathrm{E}-01$ & $2.06 \mathrm{E}-02$ & $5.67 \mathrm{E}-02$ & $3.13 \mathrm{E}-04$ & $1.61 \mathrm{E}+00$ & $3.35 \mathrm{E}-02$ & $7.89 \mathrm{E}-03$ & $\overline{4.00 \mathrm{E}-06}$ \\
\hline @55 & $\omega$ & $-1.41 \mathrm{E}-01$ & $0.00 \mathrm{E}+00$ & $2.68 \mathrm{E}-03$ & $\overline{5.76 \mathrm{E}-07}$ & $-1.97 \mathrm{E}-01$ & $0.00 \mathrm{E}+00$ & $\overline{1.22 \mathrm{E}-02}$ & $\overline{1.00 \mathrm{E}-05}$ & $-1.11 \mathrm{E}-01$ & $0.00 \mathrm{E}+00$ & $\overline{3.05 \mathrm{E}-03}$ & $\overline{9.77 \mathrm{E}-07}$ & $\overline{-3.47 \mathrm{E}-01}$ & $\overline{1.61 E-02}$ & $2.54 \mathrm{E}-03$ & $\overline{4.29 \mathrm{E}-07}$ & $-5.13 \mathrm{E}-01$ & $4.87 \mathrm{E}-02$ & $\overline{1.65 \mathrm{E}-02}$ & $2.81 \mathrm{E}-05$ & $-2.84 \mathrm{E}-01$ & $\overline{1.61 \mathrm{E}-02}$ & $4.82 \mathrm{E}-03$ & $\overline{2.52 \mathrm{E}-06}$ \\
\hline $\mathrm{Hz}$ & $\phi$ & $-1.71 \mathrm{E}+00$ & $0.00 \mathrm{E}+00$ & $2.67 \mathrm{E}-03$ & $2.87 \mathrm{E}-07$ & $3.73 \mathrm{E}-01$ & $0.00 \mathrm{E}+00$ & $1.34 \mathrm{E}-02$ & $1.11 \mathrm{E}-05$ & $2.55 \mathrm{E}+00$ & $0.00 \mathrm{E}+00$ & $3.04 \mathrm{E}-03$ & $4.14 \mathrm{E}-07$ & $-2.32 \mathrm{E}+00$ & $2.26 \mathrm{E}-02$ & $2.85 \mathrm{E}-03$ & $5.58 \mathrm{E}-07$ & $-3.56 \mathrm{E}-01$ & $1.95 \mathrm{E}-02$ & $2.16 \mathrm{E}-02$ & $2.63 \mathrm{E}-05$ & $1.98 \mathrm{E}+00$ & $\overline{0.00 \mathrm{E}+00}$ & $4.87 \mathrm{E}-03$ & $1.06 \mathrm{E}-06$ \\
\hline-3 & $\omega$ & $2.08 \mathrm{E}+00$ & $9.77 \mathrm{E}-02$ & $1.46 \mathrm{E}-03$ & $1.60 \mathrm{E}-07$ & $1.80 \mathrm{E}+00$ & 1.09E-01 & $1.34 \mathrm{E}-02$ & $1.22 \mathrm{E}-05$ & $1.85 \mathrm{E}+00$ & 1.41E-01 & $6.30 \mathrm{E}-03$ & $4.35 \mathrm{E}-06$ & $2.15 \mathrm{E}+00$ & $\begin{array}{c}9.77 \mathrm{E}-02 \\
\end{array}$ & $2.82 \mathrm{E}-03$ & 5.99E- -07 & $2.31 \mathrm{E}+00$ & $\overline{1.03 \mathrm{E}-01}$ & $2.77 \mathrm{E}-02$ & $9.55 \mathrm{E}-05$ & $1.86 \mathrm{E}+00$ & 1.41E-01 & $1.02 \mathrm{E}-02$ & $1.15 \mathrm{E}-05$ \\
\hline $\mathrm{Hz}$ & $\phi$ & $\overline{-2.69 \mathrm{E}+01}$ & 1.29E- 01 & $1.16 \mathrm{E}-02$ & $1.52 \mathrm{E}-05$ & $-2.35 \mathrm{E}+01$ & $9.63 \mathrm{E}-02$ & $4.28 \mathrm{E}-02$ & $1.23 \mathrm{E}-04$ & $\overline{-2.44 \mathrm{E}+01}$ & $\overline{1.46 \mathrm{E}-01}$ & $8.09 \mathrm{E}-03$ & $3.17 \mathrm{E}-06$ & $\overline{-2.75 \mathrm{E}+01}$ & $1.29 \mathrm{E}-01$ & $2.81 \mathrm{E}-02$ & $9.58 \mathrm{E}-05$ & $-2.43 \mathrm{E}+01$ & $9.49 \mathrm{E}-02$ & $7.73 \mathrm{E}-02$ & $4.13 \mathrm{E}-04$ & $-2.51 \mathrm{E}+01$ & $1.46 \mathrm{E}-01$ & $1.30 \mathrm{E}-02$ & $9.91 \mathrm{E}-06$ \\
\hline+5 & $\omega$ & $-3.02 \mathrm{E}+00$ & $1.36 \mathrm{E}-01$ & $2.68 \mathrm{E}-03$ & $5.75 \mathrm{E}-07$ & $-2.21 \mathrm{E}+00$ & $1.19 \mathrm{E}-01$ & $1.23 \mathrm{E}-02$ & $1.00 \mathrm{E}-05$ & $-3.18 \mathrm{E}+00$ & $\overline{1.63 \mathrm{E}-01}$ & $3.05 E-03$ & $9.77 \mathrm{E}-07$ & $-2.99 \mathrm{E}+00$ & $\overline{1.36 \mathrm{E}-01}$ & $2.48 \mathrm{E}-03$ & $4.27 \mathrm{E}-07$ & $-2.27 \mathrm{E}+00$ & $1.19 \mathrm{E}-01$ & $1.65 \mathrm{E}-02$ & $2.81 E-05$ & $-3.15 \mathrm{E}+00$ & $1.63 \mathrm{E}-01$ & $4.83 \mathrm{E}-03$ & $2.52 \mathrm{E}-06$ \\
\hline $\mathrm{Hz}$ & $\phi$ & $4.20 \mathrm{E}+01$ & $\overline{1.50 \mathrm{E}-01}$ & $2.66 \mathrm{E}-03$ & $2.86 \mathrm{E}-07$ & $3.91 \mathrm{E}+01$ & $1.59 \mathrm{E}-01$ & $1.34 \mathrm{E}-02$ & $1.11 \mathrm{E}-05$ & $\overline{4.85 \mathrm{E}+01}$ & $1.55 \mathrm{E}-01$ & $3.04 \mathrm{E}-03$ & $4.14 \mathrm{E}-07$ & $4.16 \mathrm{E}+01$ & $1.50 \mathrm{E}-01$ & $2.82 \mathrm{E}-03$ & $5.57 \mathrm{E}-07$ & $3.86 \mathrm{E}+01$ & $1.59 \mathrm{E}-01$ & $2.16 \mathrm{E}-02$ & $2.63 \mathrm{E}-05$ & $4.80 \mathrm{E}+01$ & $1.55 \mathrm{E}-01$ & $4.88 \mathrm{E}-03$ & $1.06 \mathrm{E}-06$ \\
\hline
\end{tabular}


Table 4. Results from conventional tests over SRF-PLL systems with $T_{\mathrm{MAF}}=T_{\mathrm{HB}}$. Underlined values are those worse than the "reference" whereas boldfaced ones are those better, both by 20\%; grayed out values are considered to exhibit similar performance. MAF-PLLs are tested against non-filtered PLLs and HB-PLLs against MAF-PLLs. For the sake of brevity and data homogenization, a shorthand for scientific notation is used, i.e., $a \times 10^{b}=a \mathrm{E} b$.

\begin{tabular}{|c|c|c|c|c|c|c|c|c|c|c|c|c|c|c|c|c|c|c|c|c|c|c|c|c|c|}
\hline & & \multicolumn{4}{|c|}{ MAF-Delay } & \multicolumn{4}{|c|}{ MAF-Deriv } & \multicolumn{4}{|c|}{ MAF-Park } & \multicolumn{4}{|c|}{ HB-Delay } & \multicolumn{4}{|c|}{ HB-Deriv } & \multicolumn{4}{|c|}{ HB-Park } \\
\hline & & os & ST & PK & EN & os & ST & PK & EN & os & ST & PK & EN & os & ST & PK & EN & os & ST & PK & EN & os & ST & PK & EN \\
\hline \multirow[t]{2}{*}{$-20^{\circ}$} & $\omega$ & $3.14 \mathrm{E}+00$ & 9.94E-02 & $4.06 \mathrm{E}-04$ & $2.06 \mathrm{E}-08$ & $3.00 \mathrm{E}+00$ & $9.29 \mathrm{E}-02$ & $4.62 \mathrm{E}-04$ & $2.66 \mathrm{E}-08$ & $2.80 \mathrm{E}+00$ & $1.00 \mathrm{E}-01$ & $1.66 \mathrm{E}-03$ & $3.46 \mathrm{E}-07$ & $3.07 \mathrm{E}+00$ & $1.14 \mathrm{E}-01$ & $5.30 \mathrm{E}-04$ & $2.28 \mathrm{E}-08$ & $3.35 \mathrm{E}+00$ & 1.19E-01 & $7.67 \mathrm{E}-04$ & $3.59 E-08$ & $2.95 \mathrm{E}+00$ & $1.19 \mathrm{E}-01$ & $1.78 \mathrm{E}-03$ & $3.18 \mathrm{E}-07$ \\
\hline & $\phi$ & $9.57 \mathrm{E}+00$ & $1.03 E-01$ & $2.33 \mathrm{E}-04$ & $6.78 \mathrm{E}-09$ & $8.52 \mathrm{E}+00$ & $1.08 \mathrm{E}-01$ & $2.65 \mathrm{E}-04$ & $8.76 \mathrm{E}-09$ & $1.22 \mathrm{E}+01$ & $1.02 E-01$ & 9.54E-04 & $1.14 \mathrm{E}-07$ & $1.07 \mathrm{E}+01$ & $1.03 \mathrm{E}-01$ & $4.97 \mathrm{E}-04$ & . $699 \mathrm{E}-09$ & $9.63 \mathrm{E}+00$ & $1.13 \mathrm{E}-01$ & $7.71 \mathrm{E}-04$ & $1.43 \mathrm{E}-08$ & $1.42 \mathrm{E}+01$ & 1.49E-01 & $1.76 \mathrm{E}-03$ & 1.19E-07 \\
\hline \multirow[t]{2}{*}{$+90^{\circ}$} & $\omega$ & $-1.05 \mathrm{E}+01$ & 37E-01 & 04 & $2.07 \mathrm{E}-08$ & $9 \mathrm{E}+00$ & $E-01$ & 2E-04 & FE-08 & . $09 \mathrm{E}+01$ & $1.37 \mathrm{E}-01$ & $1.66 \mathrm{E}-03$ & $3.46 \mathrm{E}-07$ & $-1.00 \mathrm{E}+01$ & $1.85 \mathrm{E}-01$ & $1.06 \mathrm{E}-03$ & $6.94 \mathrm{E}-08$ & $-9.82 \mathrm{E}+00$ & $1.52 \mathrm{E}-01$ & $6.92 \mathrm{E}-04$ & $3.57 \mathrm{E}-08$ & $-1.02 E+01$ & $2.06 \mathrm{E}-01$ & $1.74 \mathrm{E}-03$ & $3.20 \mathrm{E}-07$ \\
\hline & $\varphi$ & $-2.66 \mathrm{E}+01$ & $3 \mathrm{E}-01$ & 3EE-04 & $8 E-09$ & $-2.11 \mathrm{E}+01$ & $1.31 \mathrm{E}-01$ & $2.65 \mathrm{E}-04$ & $8.75 \mathrm{E}-09$ & $-2.78 \mathrm{E}+01$ & $1.76 \mathrm{E}-01$ & $9.54 \mathrm{E}-04$ & $1.14 \mathrm{E}-07$ & $-4.30 \mathrm{E}+01$ & $1.82 \mathrm{E}-01$ & $\underline{1.04 \mathrm{E}-03}$ & $2.28 \mathrm{E}-08$ & $-3.42 \mathrm{E}+01$ & $1.86 \mathrm{E}-01$ & $\underline{7.46 \mathrm{E}-04}$ & $1.51 \mathrm{E}-08$ & $-4.44 \mathrm{E}+01$ & $1.97 \mathrm{E}-01$ & $1.72 \mathrm{E}-03$ & 1.19E-07 \\
\hline-3 & $\omega$ & $1.10 \mathrm{E}+00$ & $9.68 \mathrm{E}-02$ & $36 \mathrm{E}-03$ & 4E-06 & $82 \mathrm{E}-01$ & $77 \mathrm{E}-02$ & $1.31 \mathrm{E}-02$ & 15E-05 & $1.12 \mathrm{E}+00$ & $9.82 \mathrm{E}-02$ & .01E-02 & 4E-04 & $2.05 \mathrm{E}+00$ & $9.77 \mathrm{E}-02$ & E-04 & E- 08 & $1.57 \mathrm{E}+00$ & . $09 \mathrm{E}-01$ & $1.33 \mathrm{E}-03$ & $4 \mathrm{E}-07$ & $1.83 \mathrm{E}+00$ & $1.52 \mathrm{E}-01$ & 68E-03 & 47E-06 \\
\hline $\mathrm{Hz}$ & $\phi$ & $-1.57 \mathrm{E}+01$ & 3E-01 & $E-03$ & EE-06 & $-1.33 \mathrm{E}+01$ & 3E- 02 & 9E-03 & $6 \mathrm{E}-06$ & $-1.39 \mathrm{E}+01$ & $83 \mathrm{E}-02$ & $66 \mathrm{E}-02$ & $E-04$ & $2.65 \mathrm{E}+01$ & $1.29 \mathrm{E}-01$ & $7.05 E-04$ & $2.10 \mathrm{E}-08$ & $-2.30 \mathrm{E}+01$ & $9.66 \mathrm{E}-02$ & $1.25 \mathrm{E}-03$ & $7.56 \mathrm{E}-08$ & $-2.40 \mathrm{E}+01$ & $1.46 \mathrm{E}-01$ & $4.96 \mathrm{E}-03$ & $1.02 \mathrm{E}-06$ \\
\hline+5 & $\omega$ & $-1.75 \mathrm{E}+00$ & $\overline{E E-02}$ & & $E-05$ & $-1.41 \mathrm{E}+00$ & $0 E-01$ & 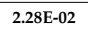 & 51E-05 & $-2.05 \mathrm{E}+00$ & $\begin{array}{l}1.03 \mathrm{E}-0 \\
\end{array}$ & & & $-3.04 \mathrm{E}+00$ & $\underline{1.36 \mathrm{E}-01}$ & & $1.22 \mathrm{E}-07$ & $-2.26 \mathrm{E}+00$ & $\begin{array}{ll}1.19 E-01 \\
\end{array}$ & & $5.53 \mathrm{E}-08$ & $-3.20 \mathrm{E}+00$ & $1.63 \mathrm{E}-01$ & $\begin{array}{c}\text { e-03 } \\
\text { s. }\end{array}$ & E- -07 \\
\hline $\mathrm{Hz}$ & $\phi$ & $3.13 \mathrm{E}+01$ & $1.18 \mathrm{E}-01$ & $5.62 \mathrm{E}-03$ & $3.95 \mathrm{E}-06$ & $2.95 \mathrm{E}+01$ & $1.00 \mathrm{E}-01$ & $1.19 \mathrm{E}-02$ & $77 \mathrm{E}-05$ & $3.72 \mathrm{E}+01$ & 1.40E-01 & $\begin{array}{l}3.89 \mathrm{E}-02 \\
\end{array}$ & $1.89 \mathrm{E}-04$ & $4.23 \mathrm{E}+01$ & $1.51 \mathrm{E}-01$ & $1.05 \mathrm{E}-03$ & $5.08 \mathrm{E}-08$ & $3.94 \mathrm{E}+01$ & $1.59 \mathrm{E}-01$ & $7.30 \mathrm{E}-04$ & $2.28 \mathrm{E}-08$ & $4.88 \mathrm{E}+01$ & $1.55 \mathrm{E}-01$ & $2.26 \mathrm{E}-03$ & $2.54 \mathrm{E}-07$ \\
\hline$\sigma^{2}=$ & $\omega$ & & $1.49 \mathrm{E}+00$ & & & & & & & $-1.33 \mathrm{E}+00$ & , & & & & & & & & & & & $-1.20 \mathrm{E}+00$ & $1.50 \mathrm{E}+00$ & $84 \mathrm{E}+00$ & $1.61 \mathrm{E}-01$ \\
\hline 0.05 & $\phi$ & $-2.11 E+00$ & $1.50 \mathrm{E}+00$ & $7.88 \mathrm{E}+00$ & $4.65 \mathrm{E}+00$ & $-1.31 E+00$ & ${ }^{1.50 \mathrm{E}+00}$ & $6.84 \mathrm{E}+00$ & $2.81 \mathrm{E}+00$ & $1.10 \mathrm{E}+00$ & $1.50 \mathrm{E}+00$ & $6.65 \mathrm{E}+00$ & $\underline{3.55 E+00}$ & $-4.91 \mathrm{E}+00$ & $1.50 \mathrm{E}+00$ & $6.84 \mathrm{E}+00$ & $3.31 \mathrm{E}+00$ & $-3.30 \mathrm{E}+00$ & $1.50 \mathrm{E}+00$ & $7.02 \mathrm{E}+00$ & $3.28 \mathrm{E}+00$ & $-1.45 \mathrm{E}+00$ & $1.50 \mathrm{E}+00$ & $7.71 \mathrm{E}+00$ & $4.14 \mathrm{E}+0 \mathrm{C}$ \\
\hline$\sigma^{2}=$ & $\omega$ & $-6.08 \mathrm{E}-01$ & +00 & 1.10 & $8-02$ & $-1.01 E+00$ & $1.50 \mathrm{E}+00$ & .00 & 22 & $-5.96 \mathrm{E}-01$ & 00 & 7. & $2.92 \mathrm{E}-02$ & 01 & 年 & & 02 & 01 & 00 & -01 & -02 & - -01 & 1.46E +00 & 81 & -02 \\
\hline 0.01 & $\phi$ & $-2.12 \mathrm{E}-01$ & +00 & $\mathrm{EE}+00$ & $1 \mathrm{E}+00$ & $1.16 \mathrm{E}+00$ & $8 B E+00$ & $8 E+00$ & $5.36 \mathrm{E}-01$ & $\overline{3.14 \mathrm{E}+00}$ & $1.49 \mathrm{E}+00$ & $2.92 \mathrm{E}+00$ & $6.96 \mathrm{E}-01$ & $E+00$ & $\mathrm{E}+00$ & $E+00$ & $6.53 \mathrm{E}-01$ & $-1.05 E+00$ & $.49 E+00$ & $3.09 \mathrm{E}+00$ & $=01$ & $8.38 \mathrm{E}-01$ & $1.50 \mathrm{E}+00$ & $2 E+00$ & 01 \\
\hline$-0.6 p$ & $\omega$ & 1.1. & $1.43 \mathrm{E}-02$ & & & 10 & $=$ & & & & 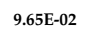 & & & & & & $728 \mathrm{E}-99$ & 1770 & & $4.55 \mathrm{E}-04$ & & & & & \\
\hline$@ 47 \mathrm{~Hz}$ & $\phi$ & $5.63 \mathrm{E}+00$ & 4 EE- 02 & $2.05 \mathrm{E}-03$ & 9E-07 & $2.75 \mathrm{E}+00$ & $00 \mathrm{E}+00$ & 19E-03 & $1.27 \mathrm{E}-06$ & $1.23 \mathrm{E}+01$ & 2.09E-01 & $\begin{array}{l}1.23 \mathrm{E}-02 \\
\end{array}$ & $1.87 \mathrm{E}-05$ & $2.99 \mathrm{E}+00$ & $9,60 \mathrm{E}-02$ & 25E-04 & $3.71 \mathrm{E}-09$ & $7.35 \mathrm{E}-01$ & $0.00 \mathrm{E}+00$ & $4.89 \mathrm{E}-04$ & $\begin{array}{r}9.92 \mathrm{E}-09 \\
\end{array}$ & $9.38 \mathrm{E}+00$ & 2.48E-01 & $2.15 \mathrm{E}-03$ & $2.53 \mathrm{E}-07$ \\
\hline$-0.6 p$ & $\omega$ & $1.06 \mathrm{E}+00$ & $\frac{2}{2}$ & $1.64 \mathrm{E}-04$ & $3.30 \mathrm{E}-09$ & $1.18 \mathrm{E}-0$ & $0.00 E+00$ & $1.85 \mathrm{E}-04$ & $4.27 \mathrm{E}-09$ & $1.93 \mathrm{E}+00$ & $\mathrm{EE}-\mathrm{C}$ & 4 & $5.53 \mathrm{E}-08$ & 9. & $3.24 \mathrm{E}-02$ & $2.85 \mathrm{E}-04$ & 09 & -02 & $0.00 \mathrm{E}+00$ & 1.99 & $4.20 \mathrm{E}$ & -00 & $8.68 \mathrm{E}-02$ & 04 & $\begin{array}{c}E-08 \\
0\end{array}$ \\
\hline ar & $\phi$ & $5.54 \mathrm{E}+00$ & 4E-02 & 1.0 & 09 & $2.93 \mathrm{E}+00$ & $0.00 E+00$ & $1.06 \mathrm{E}-04$ & $1.40 \mathrm{E}-09$ & $1.20 \mathrm{E}+01$ & $2.078-01$ & $4.39 \mathrm{E}-04$ & $86 \mathrm{E}-08$ & $2.56 \mathrm{E}+00$ & $9.511-022$ & $2.96 \mathrm{E}-04$ & $2.99 \mathrm{E}-09$ & 7.75E-01 & $00 \mathrm{E}+00$ & $1.87 \mathrm{E}-04$ & $1.43 \mathrm{E}-09$ & $8.96 \mathrm{E}+00$ & 2.46E-01 & $1.29 \mathrm{E}-03$ & 7.99E- 08 \\
\hline$-0.6 \mathrm{p}$ & $\omega$ & 8.28E-01 & 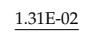 & 20 & & $10 \mathrm{E}-02$ & $0.00 \mathrm{E}+00$ & $\mathrm{ZE}-0 \mathrm{3}$ & .04t-vo & $9 \mathrm{E}+00$ & 4E-02 & $2.98 \mathrm{E}-02$ & & $8.82 \mathrm{E}-01$ & $3.24 \mathrm{E}-02$ & & 2.07E-08 & & & 8E-04 & 1 & $1.80 \mathrm{E}+00$ & 8.68E-02 & & \\
\hline$\omega_{5} \mathrm{~Hz}$ & $\omega_{-1}$ & $5.75 \mathrm{E}+00$ & $7.78 \mathrm{E}-02$ & $2.25 \mathrm{E}-03$ & $30 \mathrm{E}-07$ & $3.22 \mathrm{E}+00$ & $0.00 \mathrm{E}+00$ & $1.75 \mathrm{E}-03$ & $2.82 \mathrm{E}-06$ & $1.16 \mathrm{E}+01$ & $2.04 \mathrm{E}-01$ & $1.56 \mathrm{E}-02$ & $3.02 \mathrm{E}-05$ & $1.88 \mathrm{E}+00$ & $9.65 \mathrm{E}-02$ & $5.62 \mathrm{E}-04$ & $9.98 \mathrm{E}-09$ & $8.50 \mathrm{E}-01$ & $0.00 \mathrm{E}+00$ & $2.68 \mathrm{E}-04$ & $3.54 \mathrm{E}-09$ & $8.68 \mathrm{E}+00$ & 2.44E-01 & $1.50 \mathrm{E}-03$ & $9.24 \mathrm{E}-\mathrm{T}$ \\
\hline
\end{tabular}

Table 5. Results from two harmonics tests over SRF-PLL systems with $T_{\mathrm{MAF}}=T_{\mathrm{HB}}$. Underlined values are those worse than the MAF-PLL equivalent, whereas boldfaced ones are those better, both by $20 \%$; grayed out values are considered to exhibit similar performance. For the sake of brevity and data homogenization, a shorthand for scientific notation is used, i.e., $a \times 10^{b}=a \mathrm{E} b$.

\begin{tabular}{|c|c|c|c|c|c|c|c|c|c|c|c|c|c|c|c|c|c|c|c|c|c|c|c|c|c|}
\hline & & \multicolumn{12}{|c|}{ THD $\approx 8 \%$} & \multicolumn{12}{|c|}{ THD $\approx 16 \%$} \\
\hline & & \multicolumn{4}{|c|}{ HB-Delay } & \multicolumn{4}{|c|}{ HB-Deriv } & \multicolumn{4}{|c|}{ HB-Park } & \multicolumn{4}{|c|}{ HB-Delay } & \multicolumn{4}{|c|}{ HB-Deriv } & \multicolumn{4}{|c|}{ HB-Park } \\
\hline & & os & ST & PK & EN & os & ST & PK & EN & os & ST & PK & EN & os & $\begin{array}{l}\text { ST } \\
\end{array}$ & PK & EN & os & ST & PK & EN & os & ST & PK & EN \\
\hline ه47 & $\omega$ & $-1.56 \mathrm{E}-01$ & $0.00 \mathrm{E}+00$ & $1.47 \mathrm{E}-03$ & $1.63 \mathrm{E}-07$ & $-2.52 \mathrm{E}-01$ & $1.61 \mathrm{E}-02$ & $1.34 \mathrm{E}-02$ & $1.21 \mathrm{E}-05$ & $-1.30 \mathrm{E}-01$ & $0.00 E+00$ & $6.31 \mathrm{E}-03$ & $4.37 \mathrm{E}-06$ & $-3.86 \mathrm{E}-01$ & 1.61E- 02 & $2.83 \mathrm{E}-03$ & $6.05 \mathrm{E}-07$ & $-6.79 \mathrm{E}-01$ & $1.30 \mathrm{E}-01$ & $2.78 \mathrm{E}-02$ & $9.62 \mathrm{E}-05$ & $-3.33 \mathrm{E}-01$ & $1.61 \mathrm{E}-02$ & $1.02 \mathrm{E}-02$ & $1.15 \mathrm{E}-05$ \\
\hline $\mathrm{Hz}$ & $\phi$ & $-9,49 \mathrm{E}-01$ & $0.00 \mathrm{E}+00$ & $1.16 \mathrm{E}-02$ & $1.52 \mathrm{E}-05$ & $1.51 \mathrm{E}-01$ & $0.00 \mathrm{E}+00$ & $4.27 \mathrm{E}-02$ & $1.23 \mathrm{E}-04$ & $2.05 \mathrm{E}+00$ & $0.00 E+00$ & $8.10 \mathrm{E}-03$ & $3.17 \mathrm{E}-06$ & $-1.67 \mathrm{E}+00$ & $2.67 \mathrm{E}-02$ & $2.81 \mathrm{E}-02$ & $9.58 \mathrm{E}-05$ & $-7.75 \mathrm{E}-01$ & $3.33 \mathrm{E}-02$ & $7.74 \mathrm{E}-02$ & $4.14 \mathrm{E}-04$ & $1.37 \mathrm{E}+00$ & $3.48 \mathrm{E}-02$ & $1.30 \mathrm{E}-02$ & $9.87 \mathrm{E}-06$ \\
\hline (150 & $\omega$ & $-1.52 \mathrm{E}-01$ & $0.00 \mathrm{E}+00$ & $3.81 \mathrm{E}-03$ & $1.41 \mathrm{E}-06$ & \begin{tabular}{|c|}
$.32 \mathrm{E}-01$ \\
\end{tabular} & $0.00 \mathrm{E}+00$ & $1.17 \mathrm{E}-02$ & $9.25 \mathrm{E}-06$ & $-1.17 \mathrm{E}-01$ & $0.00 \mathrm{E}+00$ & $2.39 E-03$ & $6.15 \mathrm{E}-07$ & $-3.73 \mathrm{E}-01$ & $1.61 \mathrm{E}-02$ & $9.15 \mathrm{E}-03$ & $8.78 \mathrm{E}-06$ & $-6.14 \mathrm{E}-01$ & $7.05 \mathrm{E}-02$ & $2.22 \mathrm{E}-02$ & $3.60 \mathrm{E}-05$ & $-3.09 \mathrm{E}-01$ & $1.61 \mathrm{E}-02$ & $3.95 \mathrm{E}-03$ & $1.77 \mathrm{E}-06$ \\
\hline $\mathrm{Hz}$ & $\phi$ & $-1.14 \mathrm{E}+00$ & $0.00 \mathrm{E}+00$ & $1.24 \mathrm{E}-02$ & $1.73 \mathrm{E}-05$ & $\begin{array}{r}2.34 \mathrm{E}-01 \\
\end{array}$ & $0.00 \mathrm{E}+00$ & $3.15 \mathrm{E}-02$ & $9.93 \mathrm{E}-05$ & $2.24 \mathrm{E}+00$ & $0.00 \mathrm{E}+00$ & $3.59 \mathrm{E}-03$ & $6.94 \mathrm{E}-07$ & $-1.81 \mathrm{E}+00$ & $2.51 \mathrm{E}-02$ & $3.06 \mathrm{E}-02$ & $1.09 \mathrm{E}-04$ & $-6.13 \mathrm{E}-01$ & $2.06 \mathrm{E}-02$ & $5.67 \mathrm{E}-02$ & 3.13E-04 & $1.61 \mathrm{E}+00$ & $3.35 \mathrm{E}-02$ & 7.89E-03 & $4.00 \mathrm{E}-06$ \\
\hline ه55 & $\omega$ & $-1.41 \mathrm{E}-01$ & $0.00 \mathrm{E}+00$ & $2.68 \mathrm{E}-03$ & $5.76 \mathrm{E}-07$ & \begin{tabular}{|c|}
$-1.97 \mathrm{E}-01$ \\
\end{tabular} & $0.00 \mathrm{E}+00$ & $1.22 \mathrm{E}-02$ & $1.00 \mathrm{E}-05$ & $-1.11 \mathrm{E}-01$ & $0.00 \mathrm{E}+00$ & $3.05 E-03$ & $9.77 \mathrm{E}-07$ & $-3.47 \mathrm{E}-01$ & $1.61 \mathrm{E}-02$ & $2.54 \mathrm{E}-03$ & $4.29 \mathrm{E}-07$ & $-5.13 \mathrm{E}-01$ & $4.87 \mathrm{E}-02$ & $1.65 \mathrm{E}-02$ & $2.81 \mathrm{E}-05$ & $-2.84 \mathrm{E}-01$ & $1.61 \mathrm{E}-02$ & $4.82 \mathrm{E}-03$ & $2.52 \mathrm{E}-06$ \\
\hline $\mathrm{Hz}$ & $\phi$ & $-1.71 \mathrm{E}+00$ & $0.00 \mathrm{E}+00$ & $2.67 \mathrm{E}-03$ & $2.87 \mathrm{E}-07$ & $3.73 \mathrm{E}-01$ & $0.00 \mathrm{E}+00$ & $1.34 \mathrm{E}-02$ & $1.11 \mathrm{E}-05$ & $2.55 \mathrm{E}+00$ & $0.00 \mathrm{E}+00$ & $3.04 \mathrm{E}-03$ & $4.14 \mathrm{E}-07$ & $-2.32 \mathrm{E}+00$ & $2.26 \mathrm{E}-02$ & $2.85 \mathrm{E}-03$ & $5.58 \mathrm{E}-07$ & $-3.56 \mathrm{E}-01$ & $1.95 \mathrm{E}-02$ & $2.16 \mathrm{E}-02$ & $2.63 \mathrm{E}-05$ & $1.98 \mathrm{E}+00$ & $0.00 \mathrm{E}+00$ & $4.87 \mathrm{E}-03$ & $1.06 \mathrm{E}-06$ \\
\hline-3 & $\omega$ & $2.08 \mathrm{E}+00$ & $9.77 \mathrm{E}-02$ & $1.46 \mathrm{E}-03$ & $1.60 \mathrm{E}-07$ & $1.80 \mathrm{E}+00$ & $1.09 \mathrm{E}-01$ & $1.34 \mathrm{E}-02$ & $1.22 \mathrm{E}-05$ & $1.85 \mathrm{E}+00$ & 1.41E-01 & $6.30 \mathrm{E}-03$ & $4.35 \mathrm{E}-06$ & $2.15 \mathrm{E}+00$ & $9.77 \mathrm{E}-02$ & $2.82 \mathrm{E}-03$ & 5.99E- -07 & $2.31 \mathrm{E}+00$ & $1.03 \mathrm{E}-01$ & $2.77 \mathrm{E}-02$ & $9.55 \mathrm{E}-05$ & $1.86 \mathrm{E}+00$ & $1.41 \mathrm{E}-01$ & $1.02 \mathrm{E}-02$ & 1.15E-05 \\
\hline $\mathrm{Hz}$ & $\phi$ & $-2.69 \mathrm{E}+01$ & $1.29 \mathrm{E}-01$ & $1.16 \mathrm{E}-02$ & $1.52 \mathrm{E}-05$ & $\overline{-2.35 \mathrm{E}+01}$ & $9.63 \mathrm{E}-02$ & $4.28 \mathrm{E}-02$ & $1.23 \mathrm{E}-04$ & $\overline{-2.44 \mathrm{E}+01}$ & $1.46 \mathrm{E}-01$ & $8.09 \mathrm{E}-03$ & $3.17 \mathrm{E}-06$ & $-2.75 \mathrm{E}+01$ & 1.29E-01 & $2.81 \mathrm{E}-02$ & 9.58E-05 & $-2.43 \mathrm{E}+01$ & $9,49 \mathrm{E}-02$ & $7.73 \mathrm{E}-02$ & $4.13 \mathrm{E}-04$ & $-2.51 \mathrm{E}+01$ & $1.46 \mathrm{E}-01$ & $1.30 \mathrm{E}-02$ & $9.91 \mathrm{E}-06$ \\
\hline+5 & $\omega$ & $-3.02 \mathrm{E}+00$ & $1.36 \mathrm{E}-01$ & $2.68 \mathrm{E}-03$ & $5.75 \mathrm{E}-07$ & $\overline{-2.21 \mathrm{E}+00}$ & 1.199E-01 & $1.23 \mathrm{E}-02$ & $1.00 \mathrm{E}-05$ & $-3.18 \mathrm{E}+00$ & $\overline{1.63 \mathrm{E}-01}$ & $3.05 \mathrm{E}-03$ & $9.77 \mathrm{E}-07$ & $-2.99 \mathrm{E}+00$ & $1.36 \mathrm{E}-01$ & $2.48 \mathrm{E}-03$ & $4.27 \mathrm{E}-07$ & $-2.27 \mathrm{E}+00$ & 1.19E- 01 & $1.65 \mathrm{E}-02$ & $2.81 \mathrm{E}-05$ & $\overline{-3.115 E+00}$ & 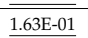 & $4.83 \mathrm{E}-03$ & $2.52 \mathrm{E}-06$ \\
\hline $\mathrm{Hz}$ & $\phi$ & $4.20 \mathrm{E}+01$ & $1.50 \mathrm{E}-01$ & $2.66 \mathrm{E}-03$ & $2.86 \mathrm{E}-07$ & $3.91 \mathrm{E}+01$ & $1.59 \mathrm{E}-01$ & $34 \mathrm{E}-02$ & $1.11 \mathrm{E}-05$ & $\overline{4.85 \mathrm{E}+01}$ & $1.55 \mathrm{E}-01$ & $3.04 \mathrm{E}-03$ & $4.14 \mathrm{E}-07$ & $\overline{4.16 \mathrm{E}+01}$ & $1.50 \mathrm{E}-01$ & $2.82 \mathrm{E}-03$ & $5.57 \mathrm{E}-07$ & $3.86 \mathrm{E}+01$ & $1.59 \mathrm{E}-01$ & $2.16 \mathrm{E}-02$ & $2.63 \mathrm{E}-05$ & $\overline{4.80 \mathrm{E}+01}$ & $1.55 \mathrm{E}-01$ & $4.88 \mathrm{E}-03$ & $1.06 \mathrm{E}-06$ \\
\hline
\end{tabular}


For the second set of tests primarily related to frequency disturbances-see Tables 3 and 5 -it can be shown that the HB-PLLs consistently outperform their MAF counterparts. The OS and ST measurements are comparable overall, whereas the PK and EN are indeed better. It is noteworthy that setting $T_{\mathrm{HB}}=T_{\mathrm{MAF}}$ not only affects the dynamic performance. Tests considering no frequency change form $50 \mathrm{~Hz}$ would offer notching possibilities to the MAF alternatives-namely, rows 1, 2, 5, 6, and 8 in Tables 2 and 4, and row 2 in Tables 3 and 5-enabling a clear advantage for them at the PK and EN tests. Nonetheless, even in those cases, the HB alternatives reach the MAF performance in most cases, and if not, the HB resulting PK and EN tests are always are quite small and acceptable.

\section{Discussion}

The HB-based PLLs were shown to be a relevant alternative to MAF-PLLs, mostly in the context of spectral disturbances. However, they are constrained to specific operating conditions derived from their discrete foundation itself. Indeed, they exhibit better stop-band characteristics than the MAF. However, the associated phase-lag forces the loop to slow down, then affecting not only the overall speed but hindering the PI performance. Therefore, there is a trade-off consisting of the required $f_{s}$ and the resulting low-frequencies phase. Nonetheless, a system prone to spectral disturbances would be highly benefited from the usage of HBs, especially when disturbances are high.

It is essential to consider that this proposal has avoided modifying the PLLs structures to show its direct advantages on a conspicuous scenario-non-adaptive SRF-PLLs. However, the integration of the proposed HB in different topologies could nourish an area that has been dominated by MAF and CDSC-based approaches, whenever harmonic resistance is paramount. Indeed, recent research has focused on addressing harmonic content through the referred techniques. Most of such work analyzes three-phase systems and includes adaptive loops.

In the work of Huang and Rajashekara [16], a single DSC, a MAF, and a linear transfer function in-loop are used. Besides being an adaptive proposal, a test considering harmonic distortion together with a frequency jump was not presented. Similarly, Li, et al. [17] use a MAF with a modified CDSC, also in an adaptive fashion, delivering a settling time around one cycle for jumps of $+5 \mathrm{~Hz}$ and $+40^{\circ}$. Finally, Gude and Chu [18] show an approach that uses not a cascaded but an additive approach to attain the DSC behavior. They state that their proposal fails to completely eliminate disturbances whenever harmonics are combined with frequency deviations due to the non-adaptiveness of their proposed DSC alternative. This fact applies to MAF designs overall [24].

Mainly, it can be seen that adaptiveness is preeminent in proposals aiming at harmonics filtering. This approach is now customary in works directed at improving the PLLs' dynamic performance, taking the harmonics elimination for granted by using adaptive MAFs. For instance, Zarei and Karimadini [25] propose adding "initial phase-angle detectors" and adaptive MAFs, pursuing dynamic enhancements. Similarly, Vukadinović, et al. [26] propose a PLL based on Hedge-Algebra-involving Fuzzy Logic-for which its tuning parameters are adjusted through an evolutionary algorithm, depending on the expected disturbance. In this case, resistance to the harmonic content is not even tested.

Then, the MR filtering, as shown in this work, poses an alternative to attain the suppression of frequency disturbances even for off-nominal operating points, without needing an adaptive loop. Its dynamic behavior, subject of further research in this line, can be enhanced as that of proposals based on the adaptive MAF. For instance, the HB can be taken outside of the loop, as for the EPMAF-PLL, explored in [24], or the topologies in [10,25]. Likewise, the approach taken by Xie, et al. [27] would enable preserving the current HB-PLL structure, i.e., having the HB in-loop. In that work, a predictive rule is applied to enhance the dynamic performance of a MAF-PLL, also modifying the MAF window on-line.

On the other hand, the PI values were derived from continuous-domain assumptions, yielding a sufficient-and customary - tuning approach in line with most SRF-PLL literature. Yet, the HB-PLLs obtained a more favorable comparative when tested at $T_{\mathrm{MAF}}=T_{\mathrm{HB}}$, implying that the tuning is not 
sufficiently independent of SR as customarily assumed. The analysis and fine-tuning of the controller in such cases is one open opportunity for the further enhancement of the HB-PLLs.

\section{Conclusions}

The incorporation of multi-rate systems in the synchronization context through SRF-PLLs has been presented as a novel alternative to MAF-based PLLs. Half-band, multi-rate, elliptical filtering was added to customary PLLs to deal with power systems suffering from severe spectral perturbations and disturbances. Unlike MAF-PLLs, this proposal does not need an additional adaptive loop to deal with frequency variations and can be incorporated by just changing the MAF with an HB block-wise. After thoroughly testing the HB-PLLs, their intended use as non-adaptive filters for SRF-PLLs applications when considering substantial spectral distortions at off-nominal frequency operation is confirmed, outperforming their MAF counterparts in terms of harmonics elimination. Nonetheless, such improvement comes at the cost of mild dynamic degradation, translated as a higher loop's sensitivity and lower response speed.

Author Contributions: Conceptualization, L.I.; data-curation, L.I.; formal analysis, L.I.; funding acquisition, A.M.; investigation, L.I.; methodology, L.I.; project administration, P.P. and A.M.; resources, A.M.; software, L.I.; supervision, P.P and R.A.; validation, P.P. and R.A.; visualization, L.I.; writing-original draft preparation, L.I.; writing - review and editing, L.I. All authors have read and agreed to the published version of the manuscript.

Funding: This research received no external funding.

Conflicts of Interest: The authors declare no conflict of interest.

\section{Abbreviations}

The following abbreviations are used in this manuscript:

$\begin{array}{ll}\text { ADC } & \text { Analog to digital converter } \\ \text { CDSC } & \text { Cascaded delayed signal cancellation blocks } \\ \text { DSP } & \text { Digital signal processor } \\ \text { EN } & \text { Energy during steady-state } \\ \text { HB } & \text { Half-band elliptical filter } \\ \text { IIR } & \text { Infinite-impulse response } \\ \text { LOH } & \text { Low-order harmonics } \\ \text { LPF } & \text { Low-pass filter } \\ \text { MAF } & \text { Moving average filter } \\ \text { MR } & \text { Multi-rate } \\ \text { OS } & \text { Overshoot } \\ \text { OSG } & \text { Orthogonal signal generator } \\ \text { PI } & \text { Proportional-integral controller } \\ \text { PID } & \text { Proportional-integral-derivative controller } \\ \text { PK } & \text { Peak-to-peak amplitude during steady-state } \\ \text { PLL } & \text { Phase-locked loop } \\ \text { SR } & \text { Sampling rate } \\ \text { SRF } & \text { Synchronous reference frame } \\ \text { ST } & \text { Settling time } \\ \text { THD } & \text { Total harmonic distortion } \\ \text { ZOH } & \text { Zero-order hold }\end{array}$

\section{References}

1. Alliance, G. The Future of the Grid Evolving to Meet America's Needs-Final Report: An Industry-Driven Vision of the 2030 Grid and Recommendations for a Path Forward. 2014. Available online: https:/ / www.smartgrid.gov / document/future_grid_evolving_meet_americas_needs_final_report_ industry_driven_vision_2030_grid_and.html (accessed on 16 March 2017). 
2. Al Abri, R.S.; El-Saadany, E.F.; Atwa, Y.M. Optimal Placement and Sizing Method to Improve the Voltage Stability Margin in a Distribution System Using Distributed Generation. IEEE Trans. Power Syst. 2013, 28, 326-334. [CrossRef]

3. Lima, F.K.d.A.; Araujo, R.G.; Tofoli, F.L.; Branco, C.G.C. A Phase-Locked Loop Algorithm for Single-Phase Systems With Inherent Disturbance Rejection. IEEE Trans. Ind. Electron. 2019, 66, 9260-9267. [CrossRef]

4. Mellouli, M.; Hamouda, M.; Slama, J.B.H. A comparative Study And Evaluation of Improved MAF- PLL Algorithms. Int. J. Renew. Energy Res. 2017, 7, 88-95.

5. Han, Y.; Luo, M.; Zhao, X.; Guerrero, J.M.; Xu, L. Comparative Performance Evaluation of Orthogonal-Signal-Generators-Based Single-Phase PLL Algorithms-A Survey. IEEE Trans. Power Electron. 2016, 31, 3932-3944. [CrossRef]

6. Han, Y.; Luo, M.; Chen, C.; Jiang, A.; Zhao, X.; Guerrero, J.M. Performance Evaluations of Four MAF-Based PLL Algorithms for Grid-Synchronization of Three-Phase Grid-Connected PWM Inverters and DGs. J. Power Electron. 2016, 16, 1904-1917. [CrossRef]

7. Ghoshal, A.; John, V. Performance evaluation of three phase SRF-PLL and MAF-SRF-PLL. Turk. J. Electr. Eng. Comput. Sci. 2015, 23, 1781-1804. [CrossRef]

8. Golestan, S.; Ramezani, M.; Guerrero, J.M.; Freijedo, F.D.; Monfared, M. Moving Average Filter Based Phase-Locked Loops: Performance Analysis and Design Guidelines. IEEE Trans. Power Electron. 2014, 29, 2750-2763. [CrossRef]

9. Arya, S.R.; Patel, M.M.; Alam, S.J.; Srikakolapu, J.; Giri, A.K. Phase lock loop-based algorithms for DSTATCOM to mitigate load created power quality problems. Int. Trans. Electr. Energy Syst. 2020, 30 , e12161. [CrossRef]

10. Golestan, S.; Guerrero, J.M.; Vasquez, J.C. A Nonadaptive Window-Based PLL for Single-Phase Applications. IEEE Trans. Power Electron. 2018, 33, 24-31. [CrossRef]

11. Ahn, C.K.; Shi, P.; You, S.H. Optimal Memory Size Formula for Moving-Average Digital Phase-Locked Loop. IEEE Signal Process. Lett. 2016, 23, 1844-1847. [CrossRef]

12. He, X.; Geng, H.; Yang, G. A Generalized Design Framework of Notch Filter Based Frequency-Locked Loop for Three-Phase Grid Voltage. IEEE Trans. Ind. Electron. 2018, 65, 7072-7084. [CrossRef]

13. Jovanovic-Dolecek, G. (Ed.) Multirate Systems: Design and Applications; Idea Group Pub: Hershey, PA, USA, 2002.

14. Ulloa Rojas, R.A. Filtros: (Aproximacion y SíNtesis); Universidad Iberoamericana: Mexico City, Mexico, 2005.

15. Golestan, S.; Ramezani, M.; Guerrero, J.M.; Monfared, M. dq-Frame Cascaded Delayed Signal CancellationBased PLL: Analysis, Design, and Comparison With Moving Average Filter-Based PLL. IEEE Trans. Power Electron. 2015, 30, 1618-1632. [CrossRef]

16. Huang, Q.; Rajashekara, K. An Improved Delayed Signal Cancellation PLL for Fast Grid Synchronization Under Distorted and Unbalanced Grid Condition. IEEE Trans. Ind. Appl. 2017, 53, 4985-4997. [CrossRef]

17. Li, Y.; Wang, D.; Han, W.; Sun, Z.; Yuan, T. A Hybrid Filtering Stage Based Quasi-type-1 PLL under Distorted Grid Conditions. J. Power Electron. 2017, 17, 704-715. [CrossRef]

18. Gude, S.; Chu, C.C. Dynamic Performance Improvement of Multiple Delayed Signal Cancelation Filters Based Three-Phase Enhanced-PLL. IEEE Trans. Ind. Appl. 2018, 54, 5293-5305. [CrossRef]

19. Mathworks. Signal Processing Toolbox Documentation, 2019. Available online: https://www.mathworks. com/help/signal/index.html (accessed on 11 October 2019).

20. Ansari, R. Elliptic filter design for a class of generalized halfband filters. IEEE Trans. Acoust. Speech Signal Process. 1985, 33, 1146-1150. [CrossRef]

21. Guo, X.Q.; Wu, W.Y.; Gu, H.R. Phase locked loop and synchronization methods for grid-interfaced converters: A review. Prz. Elektrotechniczny 2011, 87, 182-187.

22. Pavljaevic, S.; Dawson, F. Synchronization to Disturbed Utility-Network Signals Using a Multirate Phase-Locked Loop. IEEE Trans. Ind. Electron. 2006, 53, 1410-1417. [CrossRef]

23. Mathworks. DSP System Toolbox Documentation, 2019. Available online: https://www.mathworks.com/ help/dsp/ (accessed on 28 January 2020).

24. Ali, Z.; Christofides, N.; Saleem, K.; Polycarpou, A.; Mehran, K. Performance evaluation and benchmarking of PLL algorithms for grid-connected RES applications. IET Renew. Power Gener. 2020, 14, 52-62. [CrossRef]

25. Zarei, M.; Karimadini, M. PLL with frequency and initial-phase-angle detectors: Performance analysis and speed/robustness trade-off improvement. IET Power Electron. 2019, 12, 2761-2770. [CrossRef] 
26. Vukadinović, D.; Nguyen, T.D.; Nguyen, C.H.; Vu, N.L.; Bašić, M.; Grgić, I. Hedge-Algebra-Based Phase-Locked Loop for Distorted Utility Conditions. J. Control Sci. Eng. 2019, 2019, 1-17. [CrossRef]

27. Xie, M.; Zhu, C.; Shi, B.; Yang, Y. Power Based Phase-Locked Loop Under Adverse Conditions with Moving Average Filter for Single-Phase System. J. Electr. Syst. 2017, 13, 332-347.

(C) 2020 by the authors. Licensee MDPI, Basel, Switzerland. This article is an open access article distributed under the terms and conditions of the Creative Commons Attribution (CC BY) license (http:/ / creativecommons.org/licenses/by/4.0/). 